Check for updates

Cite this: J. Mater. Chem. A, 2021, 9 , 19116

Received 18th March 2021

Accepted 16th April 2021

DOI: $10.1039 / \mathrm{d} 1 \mathrm{ta0} 2287 \mathrm{c}$

rsc.li/materials-a

\section{Redox-induced electricity for energy scavenging and self-powered sensors}

\author{
Md Al Mahadi Hasan, (D) ab Heting Wu ${ }^{\text {ab }}$ and Ya Yang (D) *abc
}

With the rapid development of technology in the modern era, the use of energy in different forms and levels has changed due to the numerous electronics devices and sensor systems utilized in society to ensure a smooth and comfortable digital life. In this journey, the use of low-power sensor devices is increasing dramatically due to the toxicity of batteries and conventional energy supply issues. Among the many solutions such as triboelectricity, piezoelectricity, thermoelectricity, and pyroelectricity, redox-induced electricity in energy scavenging and self-powered sensors is considerably appealing. This review presents a concise overview of the latest evolution in redox-based energy generation and the integration of redox-induced electricity generators with sensor devices including device performances. This review focuses on the current trends for energy solutions with alternative and sustainable energy resources such as human fluids, waste heat, thermogalvanic cells, and photoelectrochemistry, which are currently becoming research hotspots. Also, this review will provide a brief discussion about the performance enhancement techniques currently being investigated such as the modification of electrolytes, roles of redox couples, and concentration effects for a broader view to analyze the factors affecting the device output.
${ }^{a}$ CAS Center for Excellence in Nanoscience, Beijing Key Laboratory of Micro-Nano Energy and Sensor, Beijing Institute of Nanoenergy and Nanosystems, Chinese Academy of Sciences, Beijing 101400, People's Republic of China. E-mail: yayang@ binn.cas.cn

${ }^{b}$ School of Nanoscience and Technology, University of Chinese Academy of Sciences, Beijing 100049, People's Republic of China

${ }^{c}$ Center on Nanoenergy Research, School of Physical Science and Technology, Guangxi University, Nanning 530004, People's Republic of China

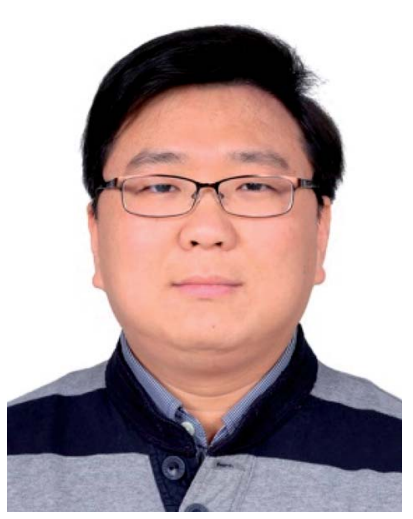

Prof. Ya Yang's main research interests focus on nanoenergy materials and devices for energy scavenging, self-powered sensing, and some new physical effects. He has published one book and more than 190 SCI academic papers in Science Advances and other journals. These papers have been cited more than 12000 times, and his H-index is 66. The research results are reported as highlights by various famous international academic media, such as The Guardian. He is the Editor-in-Chief of Nanoenergy Advances and an Editorial Committee Member of Nano-Micro Letters and some other journals. Details can be found at: http://www.researcherid.com/rid/A-72192016.

\section{Introduction}

The rate of using tiny sensing equipment ranging from smartwatches to space aircraft is several times the population growth rate. Also, all these sensing devices need continuous power supply for operation. However, the conventional power supply and frequent charging required by batteries are often very troublesome. ${ }^{1}$ Besides, environmental pollution and health hazards are still strong concerns associated with the use of traditional energy supply systems. Thus, scientists have been searching for flexible and reliable alternative power sources for low power consuming small devices and sensor networks. As reported by the European Renewable Energy Council, almost $50 \%$ of the total energy supply will be derived from renewable sources by $2040 .^{2}$ For instance, some excellent energyharvesting nanogenerators based on triboelectric, ${ }^{3-5}$ piezoelectric, ${ }^{6,7}$ pyroelectric, ${ }^{8,9}$ thermoelectric effects, ${ }^{10,11}$ and redoxinduced electricity ${ }^{12}$ have become a new hope for researchers to tackle the energy demand and toxicity of batteries. Many of these energy harvesting systems have been hybridized to achieve higher outputs by harvesting more than one sustainable energy source. ${ }^{\mathbf{1 3 - 1 6}}$ In the case of real-life applications, these energy scavenging devices have been investigated for many selfpowered sensing, detecting, and other applications, which has resulted in redox-based devices being a growing opportunity for the future. ${ }^{17-20}$ In comparison to other energy scavenging techniques, redox-based electricity generation has much more flexibility in many cases, where all other techniques are related 
to a specific condition or a sustainable energy source such as pressure for piezoelectricity and mechanical movement in triboelectricity. In contrast, redox reactions can be achieved via versatile sources such as solar energy, ambient heat, industrial waste heat, and visible and ultraviolet light, where some ionic compounds can even produce electricity in the presence of required electrodes without any other requirements.

Currently, redox chemistry is being studied and investigated in electrochemistry, thermogalvanic effects, and photochemistry from a versatile perspective among the scientific community. For a clear idea, when we searched the 'Scopus database' with the keywords "redox-based electrochemistry", "redox-based photochemical" and "thermogalvanic" we got numerous papers published each year. We summarized the total number of papers from these three search results, which showed that the increase has been significant in recent years, as shown in Fig. 1a, where dramatic changes can be noticed after 2000. However, an astonishing fact was found when we checked
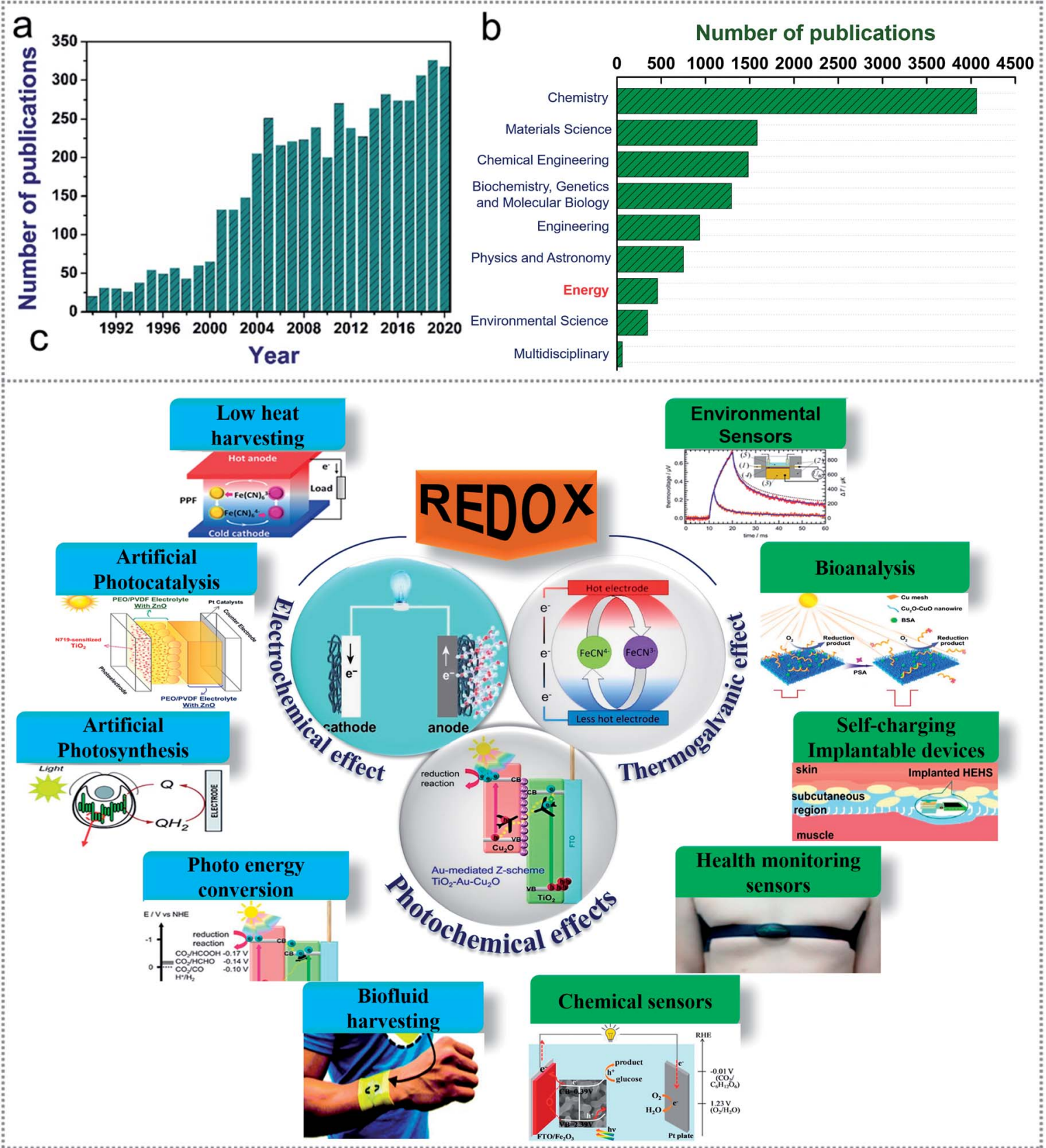

Fig. 1 Overview of the redox-based published works. (a) Redox-based publications from the last 3 decades. (b) Number of published works on redox-based devices according to notable subjects area. (c) Scope of redox-based devices in energy scavenging and self-powered sensor systems. Figures reproduced with permission from: (c) ref. 36, (c) 2020, Springer; ref. 26, ( ) 2018, the Royal Society of Chemistry; ref. 67, (c) 2021, Elsevier; ref. 99, () 2018, the Royal Society of Chemistry; ref. 90, @ 2018, the American Chemical Society; ref. 25, ( 2020, the American Chemical

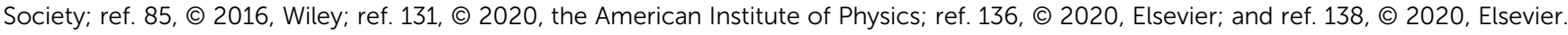


the subject area of these published papers, as illustrated in Fig. 1b. We found that very few works are being published in the "energy" subject area, indicating a dismal scenario instead of a promising future in this area. The most reported works are in chemistry, materials science, and biological field. Recently, redox-based energy-generating devices have attracted much attention for fuel cells based on human fluids, microbial fuel cells, thermogalvanic cells for harvesting waste heat, many photoelectrochemical effects such as harvesting photon energy from solar light, photocatalytic effect and water splitting, and many multifunctional and hybridized energy scavenging devices. The shortage of global energy has fueled the search for more sustainable energy sources that can be harvested with newer and improved scavenging technology. ${ }^{21}$

Several redox-based energy scavenging technologies have shown greater efficiency compared to other technologies such as heat energy scavenging through thermogalvanic cells, which can generate more output voltage than that by thermoelectric generators. Also, the required working temperature for harvesting energy through thermoelectric devices is limited due to the need for high temperature. The device fabrication cost is also cheaper and more flexible for redoxbased energy scavenging devices. Most importantly, the application area is intensely vast for redox-based devices, as shown in Fig. 1c, indicating that these devices are capable of being used almost everywhere. Nowadays, self-powered devices are the main focus in sensor networks for replacing batteries. Also, it is very easy to implement a self-powered mechanism in redox-based energy scavenging devices for a multifunctioning role. These devices also offer a stable operation due to their simple design and have a longer life than many other alternative devices. Thereby, for energy scavenging through a simple and convenient way, which can be used in health monitoring devices, wearable/implantable electronics, environmental monitoring, and sensor networks, redox-based devices are one of the most vital options for a cleaner world. Furthermore, there is no review on energy scavenging through redox chemistry in the literature. In this review, all the alternative sustainable energy sources with different techniques to apply redox reactions for energy scavenging will be discussed by dividing them into three groups, including electrochemical redox devices, thermogalvanic cells (thermocells), and photoelectrochemical redox devices with their materials, structures, and device performances. Finally, the applications of energy scavenging devices with their outputs and effective working mechanism are discussed.

\section{Introduction of redox-based energy scavenging devices}

In chemistry, electron transfer reactions between two electrodes (anode/cathode) and aqueous solution to initiate a redox reaction is are the most rudimentary and influential reactions, which are extensively investigated in several fundamental and technological research in almost all branches of scientific study. Redox is the combination of oxidation and reduction reactions, where an electron is donated and accepted at the anode and cathode respectively, and the transfer of this electron through external circuits leads to the generation of electricity. The capability of donating or accepting electrons is expressed through a numeric value termed the redox potential, which is generally calculated in relation to the standard hydrogen electrode potential $\left(E_{\mathrm{h}}\right)$ of $0 \mathrm{mV}$. Generally, the redox potential of different electrodes is measured in an aqueous solution, which defines the system as donating or accepting an electron from the hydrogen electrode, revealing the negative and positive redox potential of the system, respectively. ${ }^{22}$ For the non-aqueous solution, the redox potential with the corresponding normal hydrogen electrode (NHE) can be measured through density functional theory (DFT)-based molecular dynamics, which can be applied for both anions and cations. ${ }^{23}$

To initiate a redox reaction there must be a difference in oxidation states between the anode and cathode and the spontaneity of the reaction depends on the favorable molecular thermodynamics. Also, the reaction can be done between organic or inorganic compounds that may exist in any environmental phase (gas, liquid, and solid). Simply, it requires the exchange of one electron, where one electrode (having a lower redox potential) will donate an electron and the other electrode (having a higher redox potential) will accept the electron just like the transfer of $\mathrm{H}^{+}$in an aqueous solution for determining $\mathrm{pH}{ }^{24}$ Thereby redox-induced electricity can be generated through many ways via the capacity to govern the reaction with organic or inorganic pollutants, ${ }^{\mathbf{2 4}}$ microorganisms, applying heat energy, solar energy, and photon energy, artificial photocatalysis, photosynthesis, etc. A brief discussion to introduce all these energy scavenging devices is presented in this section.

\subsection{Electrochemistry-based redox devices to scavenge energy}

Electrochemical processes that initiate electron transfer for the change in the oxidation states of elements due to a redox reaction can be a source of electrical energy. Thus, several electrochemical redox reaction-based devices have been investigated for energy scavenging from human fluids such as sweat, ${ }^{25-27}$ glucose ${ }^{28,35}$ surrounding waste, ${ }^{42}$ and some novel device architectures, ${ }^{\mathbf{4 3 , 4 4}}$ where many inorganic and organic ionic compounds are used as the source of chemical energy. Considering its versatile scope and simple mechanisms, the applicability of redox-based energy scavenging technology is rapidly gaining importance in the scientific community. Most importantly, the fabricated self-powered energy harvesting sensor devices can be flexibly used both for human health technologies $^{32,33}$ and environment monitoring systems ${ }^{34}$ without any external energy sources that may include many toxic and harmful elements to humans and the environment. Additionally, multitasking facilities can be embellished on the fabricated devices easily without any complex modification that can reduce the output performances. ${ }^{35}$

The straightforwardness of electrochemistry-based redox reactions has led to many simple architecture devices to 


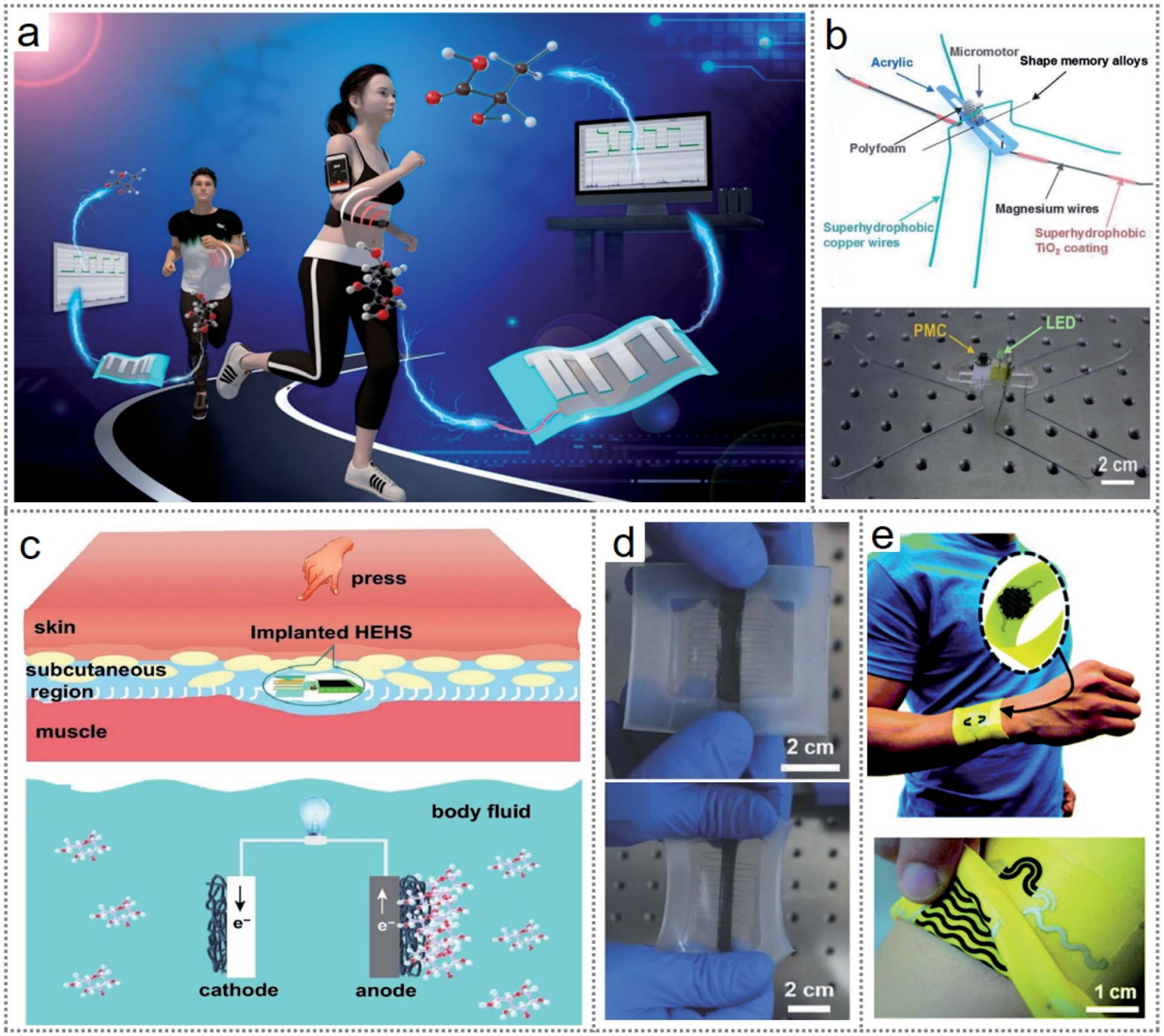

Fig. 2 Introduction of electrochemical redox-based devices. (a) Sweat-based electric energy generator by a redox reaction. (b) Image of a microrobot mimicking a water strider. (c) Schematic of an implantable hybrid device for bioenergy scavenging. (d) Redox-induced electricitydriven strain sensor. (e) Image of textile-based self-charging sweat scavenging device. Figures reproduced with permission from: (a) ref. 25 , $\odot$ 2020, the American Chemical Society; (b) ref. 30, @ 2019, Elsevier; (c) ref. 36, (c) 2020, Springer; (d) ref. 43, @ 2018, Wiley; and (e) ref. 26, @ 2018, the Royal Society of Chemistry.

scavenge energy such as sweat-based electric energy generation by the redox reaction between sweat and electrodes, as shown in Fig. 2a. ${ }^{25}$ By employing some minor modifications such as introducing hydrophobicity to different metals for the electrodes, water can be turned into a sustainable energy source by designing some novel electricity-generating devices. The water strider-mimicking microrobot (Fig. 2b) introduced by our group is capable of generating electricity via the redox reaction between water and superhydrophobic electrodes. ${ }^{30}$ The generated output could light an LED and deliver enough power for a temperature sensor. Another unique device introduced by our group can scavenge flowing water droplets to generate electricity with an electrochemistry-based redox reaction. ${ }^{31}$ Further, electrochemistry leads the energy scavenging through redox to a level where some implantable devices have also been fabricated to deliver power to many biomedical sensors and in vivo health monitoring devices. ${ }^{36,37}$ Fig. $2 \mathrm{c}$ presents an implantable hybrid bioenergy harvesting device that can generate electricity via the triboelectric effect and the redox reaction between body fluid (glucose) and electrodes. ${ }^{36}$ In the literature, numerous body fluid-harvesting devices have been investigated for bioenergy harvesting such as sweat, ${ }^{26,27}$ glucose,${ }^{35}$ intestine liquid, ${ }^{38}$ lactic acids, ${ }^{25}$ and enzymes. ${ }^{39}$ Besides, microbacterial fuel cells designed for harvesting diverse residual waste, algae, bacteria, and micro-organ-based catalysis have been reported for bioenergy scavenging through redox reactions. ${ }^{\mathbf{4 0 - 4 2}}$

Also, some inorganic elements can be exploited to harvest energy through electrochemistry-based redox reactions. 
Different oxidation states among chemical compounds lead to redox reactions, and thereby electricity is generated due to the electron movement through the electrolyte or membrane or in aqueous or solid medium. Redox-induced electricity was employed to develop a self-powered stretchable strain sensor, as shown in Fig. 2d, which provided an excellent range of sensitivity. ${ }^{\mathbf{4 3}}$ The outstanding performances and superb flexibility of wearable bioelectronic devices based on redox reactions are currently becoming a research hotspot. Bioenergy harvesting technology is currently being investigated with various efficacious technologies such as self-charging supercapacitors in wearable textile devices, as shown in Fig. 2e, which can scavenge energy from sweat and store the energy simultaneously. ${ }^{26}$ Besides, some investigations have been executed for simultaneous energy harvesting and removal of pollutants from wastewater, biodegradable co-substrates to accelerate bioelectricity generation, and extermination of microcystin virulent on electrochemically active bacteria. ${ }^{\mathbf{4 1 , 4 4}}$ An adjusted electrodialysis (ED) concept was introduced to desalinate saltwater without any external power supply; moreover, the proposed technology can generate electricity via a continuous redox reaction to the electrodes. ${ }^{45}$ However, although these versatile energy scavenging techniques indicate a convincing bright future, there are some limitations to overcome such as the low efficiency and extreme concentration dependency together with other factors affecting the stable operation of the devices. The $\mathrm{pH}$ level of the electrolyte, the surrounding temperature, and pressure can affect their output, making it challenging to provide absolute conditions for the redox reaction, especially in practical applications.

\subsection{Thermogalvanic effects for scavenging energy}

Low-grade thermal energy from the sun, industry, geothermal, and surrounding sources can be an abundant sustainable energy source for the generation of electricity. Thereby thermoelectrochemistry or temperature-dependent electrochemical processes can be a reasonable solution to utilize a significant amount of waste heat. In a thermogalvanic cell (thermoelectrochemical cell or thermocell), when the anode and cathode share a common redox-active electrolyte at separate temperatures, they can transform the temperature gradient directly into electricity through a redox reaction. ${ }^{\mathbf{4 6 4} 7}$ The generated open-circuit voltage of a thermogalvanic cell can be represented by

$$
V_{\mathrm{oc}}=S_{\mathrm{e}} \times \Delta T
$$

where $\Delta T$ represents the temperature differential and $S_{\mathrm{e}}$ denotes the Seebeck coefficient. ${ }^{48}$ The temperature dependency of the electrodes is exactly related to the entropy difference, which is represented by the following equation: ${ }^{49}$

$$
S_{\mathrm{e}}=\frac{\Delta V}{\Delta T}=\frac{\Delta S_{\mathrm{rc}}}{n F}
$$

where $\Delta V$ is the electrode potential difference, $\Delta T$ is the ultimate temperature variation across the electrodes, $n$ is the number of electrons transferred, $F$ id the Faraday constant, and
$\Delta S_{\text {rc }}$ is the entropy difference between the different oxidation and reduction states of the redox couple. The main advantage of a thermogalvanic cell over the classical thermoelectric energy generators based on semiconductor materials is the generated potential difference range given that a thermogalvanic cell produces a potential in the order of $\mathrm{mV} \mathrm{K}^{-1}$, whereas that generated by thermoelectric devices is in the order of $\mu \mathrm{V}$ $\mathrm{K}^{-1}{ }^{\mathbf{5 0 - 5 2}}$ Several favorable features of thermogalvanic cells such as low cost, flexible working mechanism, scalable tracks, higher Seebeck coefficient, balanced with low temperature, and totally carbon emission-free nature have already demonstrated their promising future in energy scavenging technology. Thereby, many thermogalvanic-based redox devices have been fabricated to scavenge body heat, industrial waste heat, automobile waste heat, solar, geothermal energy, and any possible source of waste heat in the surroundings. Therefore, redox-based thermogalvanic cells can be designed from many adaptable aspects by adjusting or tuning the characteristics of the electrodes, electrolytes, and redox couple to achieve excellent results.

Generally, thermogalvanic cells are operated in aqueous medium because the diffusion rate for the collective transfer of the redox elements needs to be accelerated by convection in liquid, which is the outcome of the density of the temperaturedependent electrolyte. ${ }^{52}$ However, for energy scavenging and practical applications, thermogalvanic cells are being designed with various structures with any possible and favorable physical states as required. A tandem device (Fig. 3a) is composed of a thermogalvanic cell that has an absorber/radiator polypyrrole (PPy) and copper foam/PEG100 as a thermal storage element to harvest environmental thermal energy during both day and night. ${ }^{53}$ To harvest industrial waste heat more cheaply, a gas electrode-based thermo-electrochemical cell has been designed for molten carbonate electrolytes, as shown in Fig. $3 b .^{54}$ Many solid-state thermogalvanic cells have been introduced to harvest poor-quality thermal energy, which is suitable for wearable energy scavenging devices and body heat harvesting. Fig. 3c shows a schematic of a solid-state thermogalvanic cell, where both electrodes are in a single hydrogen enclosure with a proton exchange membrane to directly transform heat into electricity. ${ }^{55}$

The environment-friendly nature, customizable design, reliability and noise-free operation of thermogalvanic cells are captivating scientists to investigate them more intensely. Many hybridized and multifunctioning thermogalvanic cells have been proposed for higher electrical output and stable efficiency. ${ }^{56,57}$ For harvesting light of a comparatively higher wavelength, a hybridized dye-sensitized solar cell (DSSC) and electrochemical cell (Fig. 3d) were investigated, where the efficiency increased by $32.18 \%$ compared to that of a single DSSC. ${ }^{57}$ For further improving the efficiency and practical application of multi-cell thermogalvanic systems, ${ }^{58}$ the simultaneous integration of energy harvesting with self-charging energy storage ${ }^{59}$ has been implemented. The performances of these devices are affected by several parameters and conditions including electrode porosity, photoelectron absorption, Schottky barrier, film thickness, and internal resistance. These factors need to be optimized to achieve favorable conditions for stable and spontaneous cell operation. 


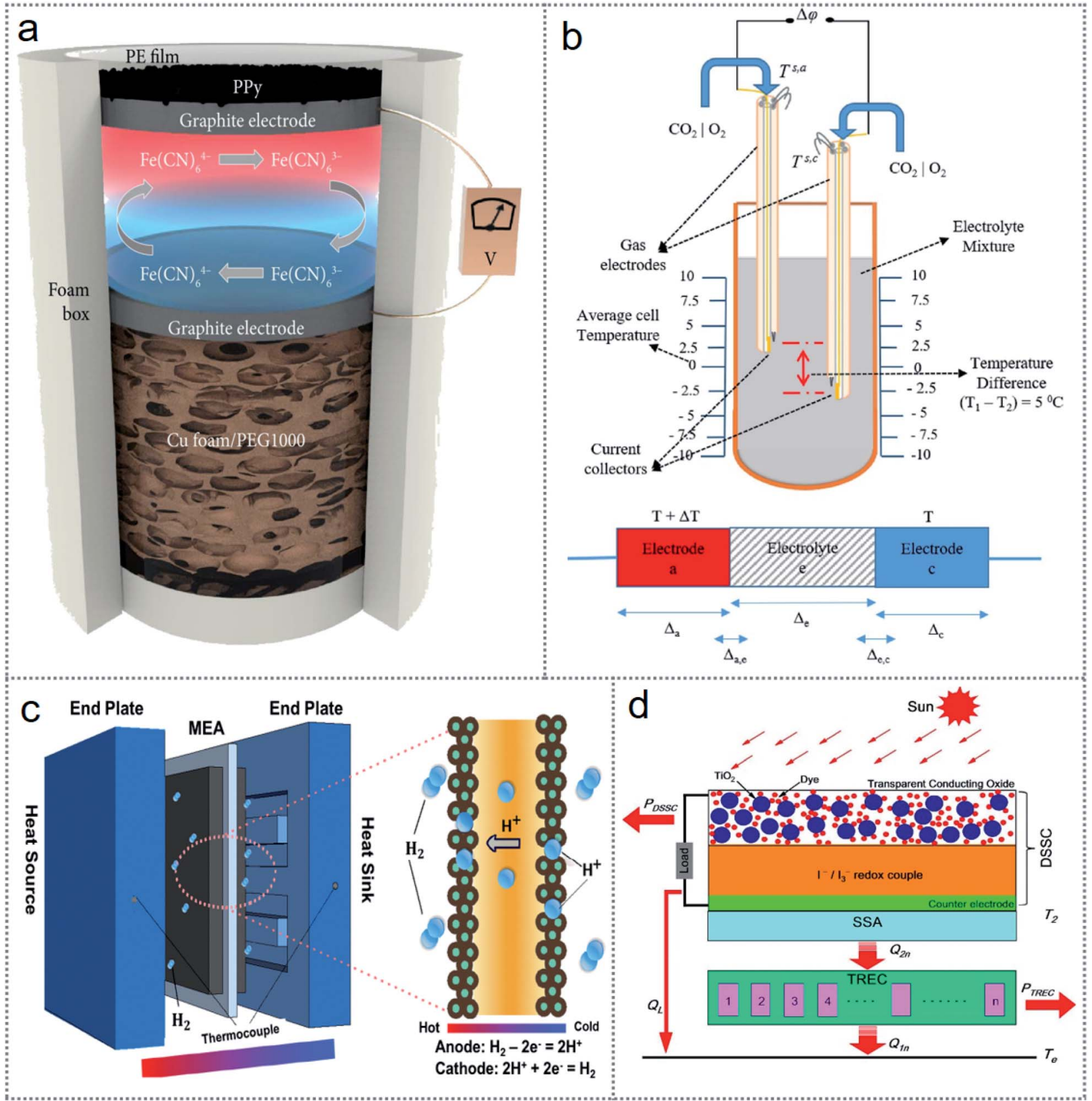

Fig. 3 Introduction of thermochemistry-based redox devices. (a) Image of a tandem thermogalvanic cell working day and night. (b) Gaselectrode-based thermogalvanic cell structure. (c) Schematic of a solid-state thermogalvanic cell. (d) Schematic of a hybridized cell consisting of a dye-sensitized solar cell and thermogalvanic cell for the simultaneous scavenging of solar energy (light and heat). Figures reproduced with permission from: (a) ref. 53, (c) 2019, Science Partner Journal; (b) ref. 54, (c) 2020, Elsevier; (c) ref. 55, (c) 2017, Elsevier; and (d) ref. 57, (c) 2019, Elsevier.

\subsection{Photoelectrochemistry-based redox devices in scavenging energy}

In the development of modern technology and building a cleaner earth, the burning of fossil fuel is a crucial challenge globally. Significantly, solar energy can be an alternative to this key issue given that only this sustainable energy source is capable of meeting the continuous energy demand. Every photon from the near-infrared, visible, and near-ultraviolet region can release 0.9 to 3.2 electron volts (87 to 308 kilojoules per mole), which can be transformed into electricity. Although photovoltaic solar cells are one of the oldest technologies to produce electricity directly with a semiconductor device, photoelectrochemistry is gaining increasing attention for energy conversion as redox (chemical) energy that can be transformed into electricity efficiently. ${ }^{60}$ By absorbing photon energy from a certain wavelength of light, an atom or molecule can initiate electron transportation to higher orbitals from lower orbitals according to the photon energy and the difference 
in the energy level between the two orbitals. Accordingly, the resulting electron-hole formed by the intramolecular species leads to excitation, where a redox reaction occurs by donating or accepting an electron by a suitable species. Also, the transmission of the electron due to the stored photon energy initiates electricity generation through a wire. ${ }^{60}$

There are several energy scavenging technologies based on the conversion of chemical (redox) energy in photoelectrochemical processes. In photoelectrochemistry, the commonly investigated energy harvesting technologies are dyesynthesized solar cells (DSSCs), photocatalytic reactions, photosynthesis (including artificial photosynthesis), and water splitting. Among them, dye-sensitized solar cells have attracted tremendous attention from researchers and many studies are being conducted with different materials and device structures. A schematic of a representative DSSC is presented in Fig. 4a, where the main components of the cell are transparent conductive oxide (TCO) to facilitate the passage of light, a thin oxide layer for charge separation, a monolayer of inorganic/ organic dye, which is absorbed on an oxide layer for incident light-harvesting, an electrolyte (including iodide $\left(\mathrm{I}^{-}\right)$/triiodide $\left(\mathrm{I}_{3}{ }^{-}\right)$) for dye-regeneration and charge separation, and

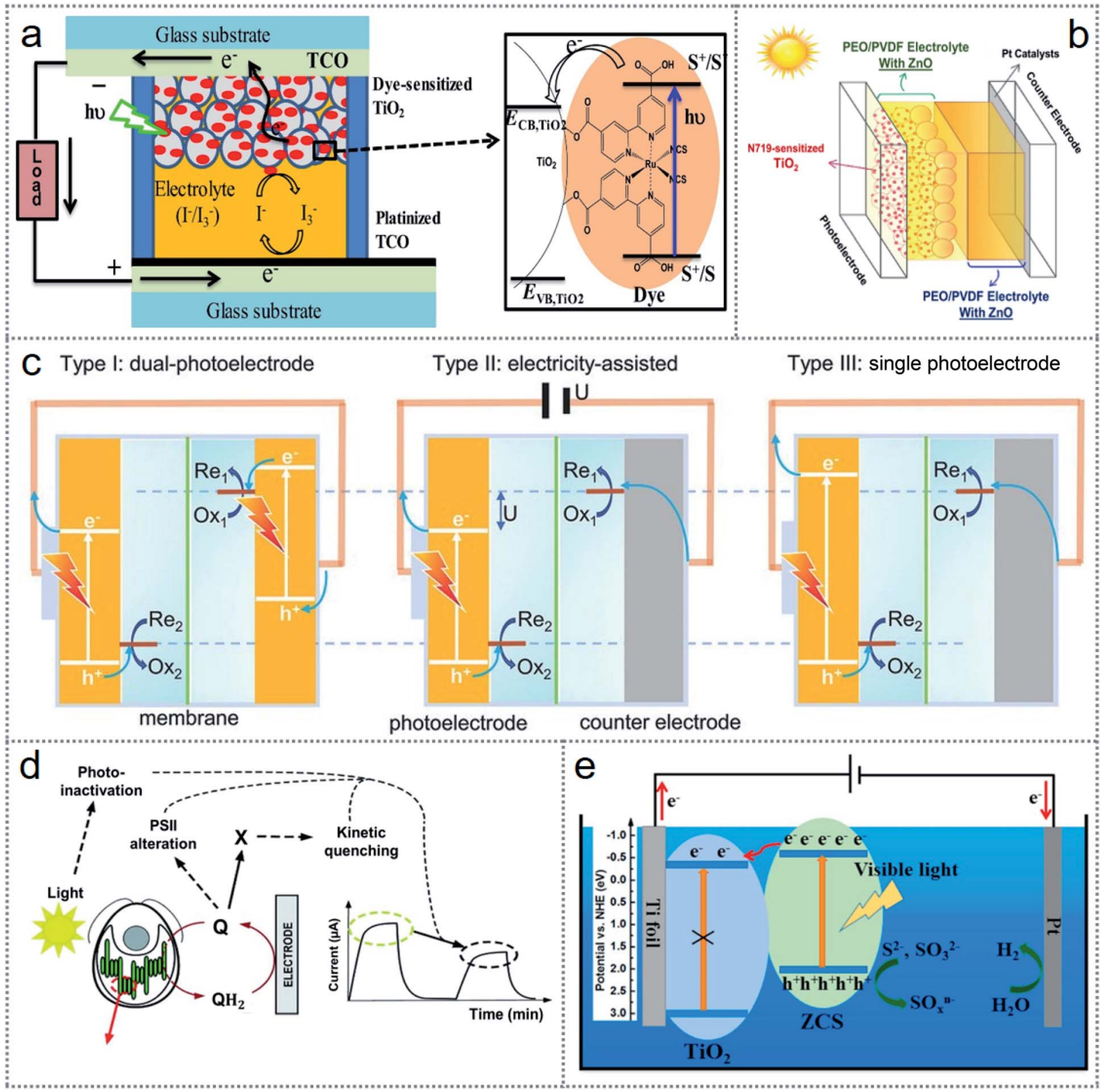

Fig. 4 Introduction of photoelectrochemistry-based redox devices. (a) Schematic representation of a dye-sensitized solar cell. (b) Schematic of a double-layered quasi-solid electrolyte-based dye-sensitized solar cell. (c) Three types of configurations for solar power redox cells. (d) Photosynthesis by Chlamydomonas reinhardtii for photocurrent generation. (e) Schematic of heterojunction photoanode-based photoelectrochemical cell. Figures reproduced with permission from: (a) ref. 61, (c) 2019, Elsevier; (b) ref. 67, (c) 2021, Elsevier; (c) ref. 71, ( ) 2016, Nature; (d) ref. 99, (c) 2018, the Royal Society of Chemistry; and (e) ref. 79, (c) 2021, Elsevier. 
a counter electrode (CE) in the transparent conductive oxide (TCO) for catalyzing the redox regeneration reaction. ${ }^{61}$ The maximum high-yielding DSSCs in the literature are based on liquid-state electrolytes. ${ }^{62,63}$ However, although liquid electrolytes have very high ionic conductivity, they limit the cell performance because they volatilize the solvent, are unfavorable for intact device assembly, and extend the possibility of dye detachment. ${ }^{64-66}$ Accordingly, recently, a double-layered quasisolid electrolyte-based DSSC was introduced, as illustrated in Fig. 4 b, which outperforms the aqueous state operation. ${ }^{67}$

In the last few decades, solar energy scavenging by water splitting for storing chemical energy as hydrogen, oxygen fuels, and hydrocarbons by photocatalytic processes and $\mathrm{CO}_{2}$ reduction has been achieved through notable attempts by scientists. ${ }^{68}$ The overall performances of these devices are not significant, but adding a secondary battery with the photoelectrochemical cell can provide an efficiency of up to $10 \%{ }^{69}$ To reduce the cost of photovoltaic cells and batteries, reversible redox reactions through photoelectrodes have been introduced to store energy, which can produce electricity from the same photoelectrochemical (PEC) cell. ${ }^{70}$ These solar-powered redox cells (SPRCs) exhibit faster oxidation/reduction reaction kinetics than water oxidation and increased efficiency both in energy conversion and storage. ${ }^{71}$ A schematic of the reported device structures of SPRCs is illustrated in Fig. 4c, where the type I configuration shows two electrodes with an accurate band structure in series operating at high voltage, ${ }^{72}$ the type II configuration needs an external biasing voltage to compensate the voltage variations among the redox couples in the anolyte and conduction band of the photoanode, ${ }^{73}$ and the type III structure has a single electrode that produces electrons and holes for oxidization and reduction of the redox couple in the catholyte and anolyte, respectively. Thus, these configurations offer a simple, low cost due to a single electrode, and effective strategy for the practical applications of SPRCs. ${ }^{74}$

Besides redox-based photoelectrochemical reactions in photosynthesis (including artificial photosynthesis), photocatalysis or any photoelectrochemical process can be utilized for energy harvesting and self-powered sensor networks. The main difference between photosynthesis and photocatalysis is that photosynthesis is thermodynamically unfavorable $(\Delta G>0)$, which needs photochemical energy to be initiated, whereas photocatalysis is thermodynamically downhill $(\Delta G<0)$ and solely speeds up with catalysts. ${ }^{75}$ The conversion of solar energy is also possible in some plants, algae, and bacteria through photosynthesis. A quinone redox mediator-based photosynthesis process was studied using a high surface electrode with Chlamydomonas reinhardtii green algae suspension, as shown in Fig. 4d. ${ }^{99}$ Photocatalytic water splitting for hydrogen production is another promising technology to scavenge solar energy as renewable hydrogen energy. ${ }^{76-78}$ A schematic of a the photoelectrochemical system is illustrated in Fig. 4e, which is based on novel heterojunction photoanodes based on $\mathrm{TiO}_{2} \mathrm{NTAs} / \mathrm{ZCS}$, resulting in improved performances compared to the single $\mathrm{TiO}_{2}$ NTAs. $^{79}$ The future of photoelectrochemical research largely depends on the technological development of novel materials and effective device structure.

\section{The fabrication materials, structures, and mechanisms of redox- based energy scavenging devices}

\subsection{Materials, structures, and mechanisms of electrochemistry-based redox devices}

Electrochemical reactions among various matters can occur regardless of physical state, temperature, and pressure alterations, which offer excellent flexibility and stability in the redoxinduced electricity generation. This allows the use of a large variety of materials as electrodes, electrolytes, and redox couples according to the requirement. From a simple metal electrode to modified electrode, as shown in Fig. 5a, superhydrophobicity was introduced for generating electricity from the rolling water on a superhydrophobic surface. ${ }^{31}$ The leftmost image in Fig. 5a depicts the SEM (scattering electron microscope) image with the magnified view in the inset (upper figure) and HRTEM (high-resolution transmission electron microscopy) image with the SADE (selected area diffraction) image (inset) (bottom figure) of the superhydrophobic surface of the $\mathrm{Cu}$ (copper) electrode. The middle and rightmost images of Fig. 5a illustrate the interaction of a water droplet with the normal $\mathrm{Cu}$ and $\mathrm{Zn}$ electrode (middle image) and superhydrophobic nanostructured surface of the electrodes (rightmost image), clarifying the role of the accelerated oxygendiffusion process to build the TPCP (three-phase contact point) for ORR (oxygen reduction reaction). Thereby, the $\mathrm{Zn}$ electrode (anode) functions as the anode, where the oxidation reaction $\left(\mathrm{Zn}-2 \mathrm{e}^{-} \rightarrow \mathrm{Zn}^{2+}\right.$ ) occurs. The overall operating principle is illustrated in Fig. $5 \mathrm{~b}$, where spontaneous oxygenreduction reaction $\left(\mathrm{O}_{2}+2 \mathrm{H}_{2} \mathrm{O}+4 \mathrm{e}^{-} \rightarrow 4 \mathrm{OH}^{-}\right)$at the $\mathrm{Cu}$ electrode (cathode) causes the electron to move through the exterior load. The governing cause influencing the performance is the discrete distribution of nanostructures (Fig. 5a), which increases the effective surface area of the electrodes, enhancing their electrochemical interaction with the liquid.

Similarly, the modification of the electrodes used in the device can be done in many ways according to the device architecture and medium of electrochemical interaction. For scavenging human sweat, an SEG (sweat-based electricity generator) was fabricated, which could generate electricity via the reactions of the electrodes with human sweat. ${ }^{25}$ To extend the device output, the electrodes were modified with SWCNTs (single-walled carbon nanotubes) and MWCNTs (multi-walled carbon nanotubes). Fig. 5c demonstrates the SEM photograph (upper leftmost image) of the SWCNTs and MWCNTs, where the surface area of the electrode increased, which improved the device performances. The lower part of Fig. 5c (leftmost image) presents a photograph of the device. The SEG architecture is depicted in Fig. 5c (middle figure), where carbon nanotube (CNT)-coated Cu (copper) is used as the cathode with a $\mathrm{Zn}$ (zinc) film as the anode. The redox-induced electricity generation occurs via the reduction reaction $\left(\mathrm{O}_{2}+2 \mathrm{H}_{2} \mathrm{O}+4 \mathrm{e}^{-} \rightarrow 4 \mathrm{OH}^{-}\right)$at the cathode and oxidation reaction $\left(\mathrm{Zn}-2 \mathrm{e}^{-} \rightarrow \mathrm{Zn}^{2+}\right)$ on the $\mathrm{Zn}$ surface, which permits the movement of electrons across the exterior circuit, as presented in Fig. 5d. Thereby, this flexibility 


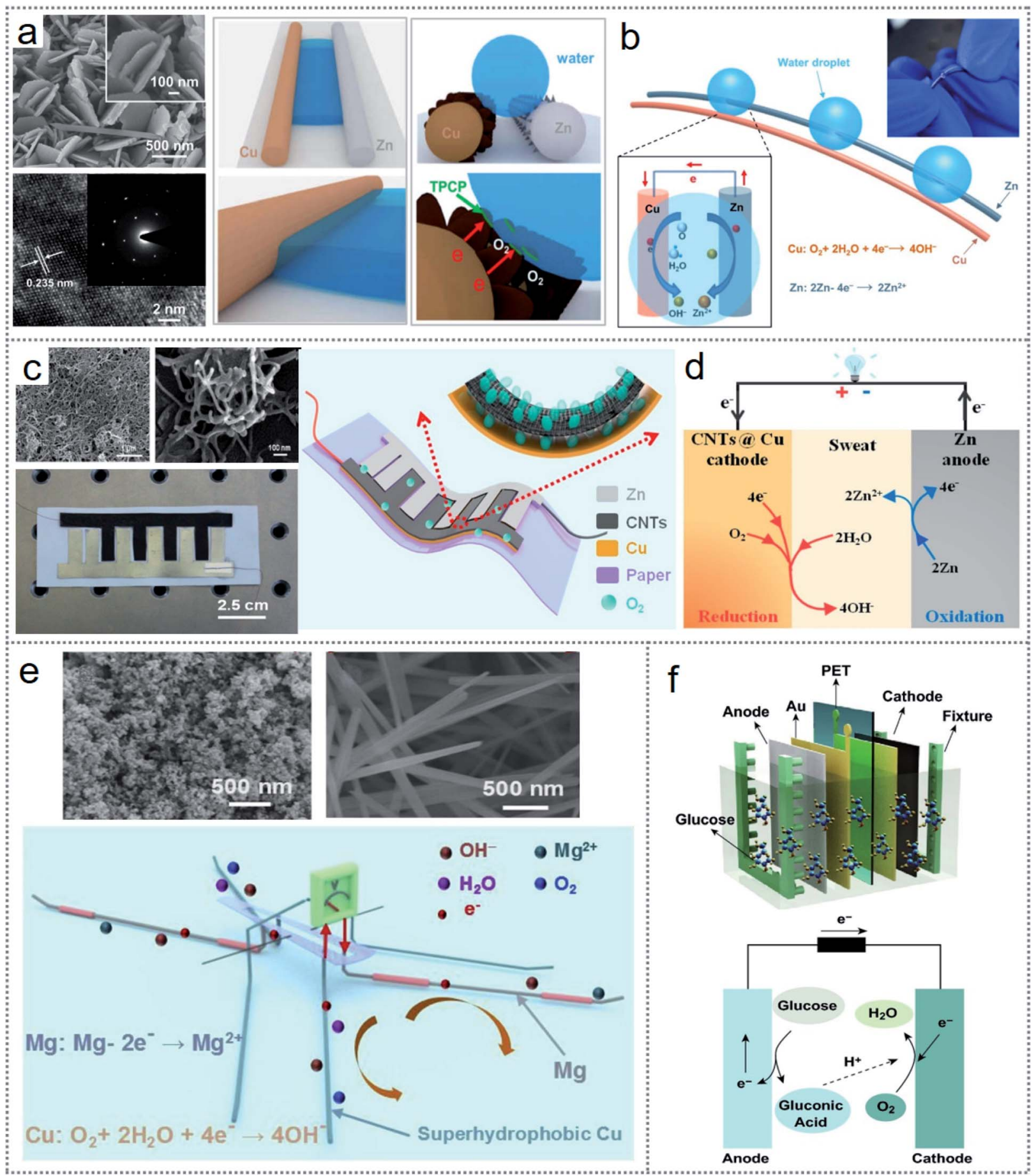

Fig. 5 Materials, structure, and operating principle of electrochemistry-based redox devices. (a) SEM and HRTEM images of the superhydrophobic surface of $\mathrm{Cu}$ (left side image), interaction of a water droplet with the Cu and Zn electrode (middle image), and TCP formation for the ORR (right side image). (b) Working principle of the fabricated device. (c) SEM images of SWCNTs and MWCNTs (left side upper image), optical image of the SEG (left side bottom image), and schematic structure of the fabricated SEG device (right side image). (d) Schematic illustration of the redox reactions for electricity generation. (e) SEM image of nanoparticle-modified electrodes (upper images) and schematic of the operating principle of the microrobot. (f) Layer-by-layer schematic structure of the implantable device (upper figure) and operating principle of the fabricated device (bottom figure). Figures reproduced with permission from: (a) and (b) ref. 31, (c) 2019, Elsevier; (c) and (d) ref. 25, (c) 2020, the American Chemical Society; (e) ref. 30, @ 2019, Elsevier; and (f) ref. 36, (c) 2020, Springer.

of the redox principle led to the design of multifunctional and self-powered floating microrobots based on the electrode interaction with water. ${ }^{30}$ Here, $\mathrm{Mg}$ (magnesium) and $\mathrm{Cu}$ wire were used as the anode and cathode, respectively, which are the artificial legs of the robot. Both electrodes were modified with nanoparticles, as shown in Fig. 5e (upper image), representing 
the SEM image of the nanoparticle-coated MG and nanorodcoated $\mathrm{Cu}$ wires. The operating principle of the microrobots is explained in Fig. 5e (bottom figure), where the $\mathrm{Mg}$ electrode undergoes an oxidation reaction $\left(\mathrm{Mg}-2 \mathrm{e}^{-} \rightarrow \mathrm{Mg}^{2+}\right)$ and the oxygen-reduction reaction $\left(\mathrm{O}_{2}+2 \mathrm{H}_{2} \mathrm{O}+4 \mathrm{e}^{-} \rightarrow 4 \mathrm{OH}^{-}\right)$occurs at the $\mathrm{Cu}$ electrode. Besides, many other materials such as graphite, carbon paper, platinum (Pt), and platinum black can be used as electrodes in redox-based energy scavenging devices such as microbial fuel cells (MFCs). ${ }^{\mathbf{4}}$ For modification purposes, carbon nanorods, carbon nanotubes, nanoparticles, and $\mathrm{MoO}_{2}$ have been reported to enhance the device performance. ${ }^{\mathbf{8 0}}$

The working mechanism of redox-based electrochemical energy scavenging depends not only on the material properties but also on the mechanically induced potential gradients. ${ }^{35}$ Accordingly, a soft, stretchable skin mountable biofuel cell was fabricated for energy harvesting from sweat with excellent power density. ${ }^{81}$ Furthermore, it has versatile scope in material selection from inorganic and organic groups, hybridization of multidimensional energy scavenging, and applications. ${ }^{36}$ An implantable hybrid energy scavenging device was fabricated, which could harvest triboelectricity from the mechanical force on the skin and electrochemical energy with the interaction with the body glucose. ${ }^{36}$ A layer-by-layer schematic drawing of the fabricated device is presented in Fig. $5 \mathrm{f}$ (upper part of the figure), including the electrochemical redox reaction (bottom part of the image) for energy scavenging. The glucose fuel cell (GFC) contains an anode, Au (gold), cathode, PET (polyethylene terephthalate) substrate, and fixture. The glucose molecules from the glucose solution will be oxidized $\left(\mathrm{C}_{6} \mathrm{H}_{12} \mathrm{O}_{6}+\mathrm{H}_{2} \mathrm{O} \rightarrow\right.$ $\left.\mathrm{C}_{6} \mathrm{H}_{12} \mathrm{O}_{7}+2 \mathrm{H}^{+}+2 \mathrm{e}^{-}\right)$at the anode and turned into gluconic acid, as illustrated in Fig. $5 \mathrm{f}$ (bottom image). Also, the reduction reaction $\left(0.5 \mathrm{O}_{2}+2 \mathrm{H}^{+}+2 \mathrm{e}^{-} \rightarrow \mathrm{H}_{2} \mathrm{O}\right)$ occurs at the cathode to complete the overall redox reaction $\left(\mathrm{C}_{6} \mathrm{H}_{12} \mathrm{O}_{6}+0.5 \mathrm{O}_{2} \rightarrow\right.$ $\mathrm{C}_{6} \mathrm{H}_{12} \mathrm{O}_{7}$ ), which causes electrons to flow from the anode to cathode. In many reported devices for bioenergy harvesting, versatile bio-electrodes from enzymes or proteins have been introduced for better biocompatibility. ${ }^{29,33,39}$ To obtain a comprehensive idea and the operation of redox-based electrochemical energy scavenging techniques, the details of functional materials, device performances, applications, and other relative information on the recently reported works are summarised in Table 1.

\subsection{Materials, structures, and mechanisms of thermogalvanic effect-based redox devices}

Thermochemistry-based redox reactions can be an excellent option for scavenging low-grade waste heat into electrical energy from industrial and surrounding sources. In thermogalvanic devices, the two electrodes remain at different temperatures in the same redox-active electrolyte and initiate a redox reaction via a temperature gradient spontaneously with the direct transformation of chemical energy into electricity. ${ }^{\mathbf{8 2}}$ The operating principle of an ordinary thermogalvanic cell is shown in Fig. 6a, where the $\mathrm{K}_{3}\left[\mathrm{Fe}(\mathrm{CN})_{6}\right] / \mathrm{K}_{3}\left[\mathrm{Fe}(\mathrm{CN})_{6}\right]$ electrolyte contains two graphite electrodes. ${ }^{48}$ When the cell is under a temperature gradient across it, the redox couple will have a reversible reaction in the opposite direction, which leads to a potential difference across the electrodes. ${ }^{83}$ Considering that the changes in entropy for any redox couple depends on the charge density, which reflects the potency of engagement between the redox couple and solvent, because it possess a greater charge density than $\left[\mathrm{Fe}(\mathrm{CN})_{6}\right]^{3-},\left[\mathrm{Fe}(\mathrm{CN})_{6}\right]^{4-}$ exhibits lower thermodynamic entropy. ${ }^{48}$ Consequently, an electron is free to move to the electrode of the heated side by the oxidation reaction of $\left[\mathrm{Fe}(\mathrm{CN})_{6}\right]^{4-}$ to $\left[\mathrm{Fe}(\mathrm{CN})_{6}\right]^{3-}$, and the reduction of $\left[\mathrm{Fe}(\mathrm{CN})_{6}\right]^{3-}$ to $\left[\mathrm{Fe}(\mathrm{CN})_{6}\right]^{4-}$ occurs at the low-temperature part of the cathode by receiving the electron through the external circuit (Fig. 6a). Thus, continuous electricity is generated in thermogalvanic cells until one of the components of the cell is degraded. ${ }^{84}$

Considering that the output of thermogalvanic cells is very low ( $\mathrm{mV}$ range), series-connected cells with positive and negative Seebeck coefficients have been reported to achieve higher voltages for practical applications. ${ }^{85}$ Given that there is a limited number of redox species, new and novel concepts are needed for excellent devices. An emerging idea of enabling $\mathrm{p}-\mathrm{n}$ conversion by using iodide/triiodide $\left(\mathrm{I}^{-} / \mathrm{I}_{3}{ }^{-}\right)$as a redox couple was induced with thermo-sensitive nanogels known as poly( $N$-isopropylacrylamide) (PNIPAM). This modification led to the extension of the $S_{\mathrm{e}}$ (Seebeck coefficients) to $-1.91 \mathrm{mV} \mathrm{K}^{-1}$ from $0.71 \mathrm{mV} \mathrm{K}^{-1} .{ }^{73}$ The working mechanism is illustrated in Fig. $6 \mathrm{~b}$, where the oxidation reaction $\left(3 \mathrm{I}^{-}-2 \mathrm{e}^{-} \rightarrow \mathrm{I}_{3}{ }^{-}\right)$occurs at the low-temperature electrode (anode) because of the change in the entropy in the negative direction and the electrons are injected across the exterior load towards the hot electrode (cathode) by the reduction reaction $\left(\mathrm{I}_{3}{ }^{-}+2 \mathrm{e}^{-} \rightarrow 3 \mathrm{I}^{-}\right)$. Due to the temperature and concentration gradient at the cold part, Brownian diffusion is initiated by the hydrophobic nanogels, which leads to an increase in $\mathrm{I}_{3}{ }^{-}$, reverting the equilibrium to the reduction reaction $\left(\mathrm{I}_{3}{ }^{-}+2 \mathrm{e}^{-} \rightarrow 3 \mathrm{I}^{-}\right)$, resulting in an n-type system. ${ }^{86}$ Nanomaterials such as graphene- and carbon nanotubemodified electrodes have been introduced in many reported thermogalvanic energy scavenging to obtain enhanced device efficiency. ${ }^{87}$ Consequently, gold nanoparticles (AuNPs) have been used in the electrode interface in gel-based thermogalvanic cells. ${ }^{\mathbf{8 8}} \mathrm{A}$ schematic of the gel-based thermogalvanic cell is presented in the $1^{\text {st }}$ part of Fig. $6 \mathrm{c}$ and the physically sandwiched AuNPs between the gel and electrodes in the $2^{\text {nd }}$ part, and the formation of gold nanoparticles throughout the gel is shown in the $3^{\text {rd }}$ part of the figure. The significance of using gold AuNPs at the electrode interface is that they can decrease the resistance between the gel and electrode to increase the output current while they have no measurable significance when they are formed throughout the gel.

The redox mechanism based on the thermogalvanic effect can lead to the development of some novel devices for scavenging energy with excellent flexibility, which can facilitate many multifunctioning opportunities. A smart thermogalvanic hydrogel was introduced, which could generate electricity from waste heat and achieve effective evaporative cooling simultaneously, as shown in Fig. $6 \mathrm{~d} .{ }^{89}$ The polymer chains are confined solidly with the polyacrylamide (PAAm) hydrogel and redox 
Table 1 Summary of electrochemical redox-based energy scavenging devices with their performance-enhancing methods, functional materials, device outputs, and applications

\begin{tabular}{|c|c|c|c|c|c|c|}
\hline $\begin{array}{l}\text { Energy scavenging } \\
\text { methods }\end{array}$ & $\begin{array}{l}\text { Performance } \\
\text { enhancing } \\
\text { techniques }\end{array}$ & Functional materials & Electrodes & Device outputs & Applications & Reference \\
\hline $\begin{array}{l}\text { Interaction between } \\
\text { the sweat and } \\
\text { electrodes }\end{array}$ & $\begin{array}{l}\text { Carbon nanotube } \\
\text { modified electrodes }\end{array}$ & Human sweat & $\begin{array}{l}\text { Copper }(\mathrm{Cu}) \text { and zinc } \\
(\mathrm{Zn})\end{array}$ & $\begin{array}{l}\text { Output current }= \\
16.58 \mathrm{~mA}, \text { power }= \\
2.2 \mathrm{~mW}\end{array}$ & $\begin{array}{l}\text { Wireless heart rate } \\
\text { sensor, lactic acid } \\
\text { monitoring }\end{array}$ & 25 \\
\hline $\begin{array}{l}\text { Interaction between } \\
\text { the water surface and } \\
\text { electrodes }\end{array}$ & $\begin{array}{l}\text { Applying } \\
\text { hydrophobicity to } \\
\text { increase aerophilicity }\end{array}$ & Water & $\begin{array}{l}\text { Copper }(\mathrm{Cu}) \text { and } \\
\text { magnesium }(\mathrm{Mg})\end{array}$ & $\begin{array}{l}\text { Voltage }=1.38 \mathrm{~V} \\
\text { current }=25 \mathrm{~mA}\end{array}$ & $\begin{array}{l}\text { Temperature sensor, } \\
\text { electronics }\end{array}$ & 30 \\
\hline $\begin{array}{l}\text { Redox reaction of } \\
\text { electrodes with } \mathrm{NaCl} \\
\text { solution }\end{array}$ & - & $\mathrm{NaCl}$ solution & $\begin{array}{l}\text { Zinc (Zn) and } \\
\text { graphene }\end{array}$ & $\begin{array}{l}\text { Voltage }=0.83 \mathrm{~V}, \\
\text { current }=75 \mu \mathrm{A}\end{array}$ & $\begin{array}{l}\text { Strain sensor, motion } \\
\text { detection }\end{array}$ & 43 \\
\hline $\begin{array}{l}\text { Hybridization of } \\
\text { TENG and glucose } \\
\text { fuel cell (GFC) }\end{array}$ & $\begin{array}{l}\text { Integration of } \\
\text { multiple energy } \\
\text { scavenging }\end{array}$ & Glucose & $\begin{array}{l}\text { Multiwalled carbon } \\
\text { nanotubes } \\
\text { (MWCNTs) and gold } \\
\text { (Au) }\end{array}$ & $\begin{array}{l}\text { Output voltage } \\
\text { (integrated) }=21.7 \mathrm{~V}, \\
\text { current }(\text { integrated })= \\
1.2 \mu \mathrm{A}\end{array}$ & $\begin{array}{l}\text { Low-power electronic } \\
\text { devices, bioenergy } \\
\text { harvesting }\end{array}$ & 36 \\
\hline $\begin{array}{l}\text { Continuous redox } \\
\text { reactions at the } \\
\text { electrodes }\end{array}$ & - & $\begin{array}{l}\mathrm{NaCl}, \mathrm{ZnCl} \text { (anolyte) } \\
\text { and } \mathrm{NaBr} \text { (catholyte) }\end{array}$ & $\begin{array}{l}\text { Zinc }(\mathrm{Zn}) \text { and } \\
\text { Bromine }\left(\mathrm{Br}_{2}\right)\end{array}$ & $\begin{array}{l}\text { Voltage, } \mathrm{V}=1.808 \mathrm{~V} \\
\text { power density }=42 \\
\mathrm{~mW} \mathrm{~cm}{ }^{-2}, \text { current } \\
\text { density }=29 \mathrm{~mA} \mathrm{~cm}^{-2}\end{array}$ & $\begin{array}{l}\text { Redox chemistries, } \\
\text { cells geometries, } \\
\text { membrane } \\
\text { technologies }\end{array}$ & 45 \\
\hline $\begin{array}{l}\text { Patch-type enzymatic } \\
\text { biofuel cell ( } p \text {-EBFC) }\end{array}$ & - & Human sweat & $\begin{array}{l}\text { Lactate oxidase (Lox) } \\
\text { (bioanode) and } \\
\text { Bilirubin oxidase } \\
\text { (BOx) (biocathode) }\end{array}$ & $\begin{array}{l}\mathrm{V}_{\mathrm{oc}}(\text { open circuit } \\
\text { voltage })=0.55 \pm \\
0.3 \mathrm{~V} \text { and } \mathrm{I}_{\mathrm{sc}}(\text { short- } \\
\text { circuit current })=140 \\
\pm 4 \mu \mathrm{A}\end{array}$ & $\begin{array}{l}\text { LED, wearable } \\
\text { sensors, digital } \\
\text { thermometers }\end{array}$ & 104 \\
\hline $\begin{array}{l}\text { Mechanistic power } \\
\text { generating } \\
\text { mechanical- } \\
\text { electrochemical } \\
\text { coupling in an } \\
\text { electrochemical } \\
\text { generator }\end{array}$ & $\begin{array}{l}\text { Using carbon } \\
\text { nanotubes (CNTs) }\end{array}$ & Prussian blue (PB) & $\begin{array}{l}\text { Platinum foil } \\
\text { (counter electrode) } \\
\text { and KCl-saturated } \\
\text { calomel (reference } \\
\text { electrode) }\end{array}$ & $\begin{array}{l}\text { Output power density } \\
=3.8 \mu \mathrm{W} \mathrm{cm}-2\end{array}$ & $\begin{array}{l}\text { Sensing media and } \\
\text { motion, health } \\
\text { monitoring } \\
\text { electronics devices }\end{array}$ & 35 \\
\hline $\begin{array}{l}\text { Power generation } \\
\text { from the human } \\
\text { respiration by } \\
\text { epidermal biofuel cell } \\
\text { (BFC) }\end{array}$ & $\begin{array}{l}\text { Using } \\
\text { tetrathiafulvalene } \\
(\mathrm{TTF}) / \text { carbon } \\
\text { nanotube (CNT) as an } \\
\text { electron shuttle }\end{array}$ & Lactate & $\begin{array}{l}\text { Lactate oxidase } \\
\text { (anode) and platinum } \\
\text { (Pt) (cathode) }\end{array}$ & $\begin{array}{l}\text { Maximum power } \\
\text { density }=70 \mu \mathrm{W} \mathrm{cm}\end{array}$ & Wearable electronics & 105 \\
\hline $\begin{array}{l}\text { Sweat harvesting } \\
\text { electronic skin-based } \\
\text { biofuel cell }\end{array}$ & $\begin{array}{l}\text { Using carbon } \\
\text { nanotube (CNT) both } \\
\text { in cathode and anode }\end{array}$ & Lactate from sweat & $\begin{array}{l}\text { CNT-NQ } \\
\text { (naphthoquinone) } \\
\text { (anode) and CNT- } \\
\mathrm{Ag}_{2} \mathrm{O} \text { (cathode) }\end{array}$ & $\begin{array}{l}\text { Output voltage }= \\
0.5 \mathrm{~V} \text {, maximum } \\
\text { power density }=1.2 \\
\mathrm{~mW} \mathrm{~cm} \mathrm{~cm}^{-2}, \text { (high } \\
\text { power under } 50 \% \\
\text { strain) }\end{array}$ & $\begin{array}{l}\text { Stretchable and soft } \\
\text { wearable devices }\end{array}$ & 81 \\
\hline $\begin{array}{l}\text { Moisture-triggered } \\
\text { energy scavenging } \\
\text { technique }\end{array}$ & $\begin{array}{l}\text { Synthesizing super } \\
\text { hygroscopic materials } \\
\text { (SHM) }\end{array}$ & $\begin{array}{l}\text { Human sweat, Co } \\
\text { (cobalt)-SHM } \\
\text { (electrolyte) }\end{array}$ & $\begin{array}{l}\text { Zinc }(\mathrm{Zn}) \text { (anode) and } \\
\text { copper }(\mathrm{Cu})(\text { cathode })\end{array}$ & $\begin{array}{l}\text { Maximum output } \\
\text { voltage, } \mathrm{V}=0.57 \mathrm{~V} \\
\text { maximum power } \\
\text { density }=0.11 \mathrm{~mW} \\
\mathrm{~cm}^{-2}\end{array}$ & $\begin{array}{l}\text { Wearable energy } \\
\text { harvesting devices } \\
\text { and powering } \\
\text { electronic devices }\end{array}$ & 27 \\
\hline $\begin{array}{l}\text { Moisture } \\
\text { management fabric } \\
\text { (MMF)-based flexible } \\
\text { biofuel cell }\end{array}$ & $\begin{array}{l}\text { Multiple fuel cells are } \\
\text { stacked to get higher } \\
\text { output }\end{array}$ & Glucose & $\begin{array}{l}\text { Glucose oxidase } \\
\text { (GOx) (anode) and } \\
\text { Prussian blue (PB) } \\
\text { (cathode) }\end{array}$ & $\begin{array}{l}\text { Open circuit voltage } \\
=1.08 \mathrm{~V}, \text { maximum } \\
\text { power }=80.2 \mu \mathrm{W}\end{array}$ & $\begin{array}{l}\text { Wearable electronics } \\
\text { and sensor devices }\end{array}$ & 106 \\
\hline $\begin{array}{l}\text { Wearable textile- } \\
\text { based hybrid } \\
\text { supercapacitor } \\
\text { biofuel cell (SC-BFC) }\end{array}$ & $\begin{array}{l}\text { Carbon nanotube } \\
\text { (CNT) for accelerating } \\
\text { electron transport }\end{array}$ & Lactate from sweat & $\begin{array}{l}\text { Lactate oxidase (LOx) } \\
\text { (anode) and Silver } \\
\text { oxide }\left(\mathrm{Ag}_{2} \mathrm{O}\right) \\
\text { (cathode) }\end{array}$ & $\begin{array}{l}\text { Maximum power } \\
\text { density }=252 \mu \mathrm{W} \\
\mathrm{cm}^{-2}\end{array}$ & $\begin{array}{l}\text { Wearable self- } \\
\text { powered textile based } \\
\text { electronics }\end{array}$ & 26 \\
\hline
\end{tabular}

couple $\left[\mathrm{Fe}(\mathrm{CN})_{6}\right]^{3-} /\left[\mathrm{Fe}(\mathrm{CN})_{6}\right]^{4-}$, staying throughout the hydrogel and converting the temperature gradient into electric power. The hydrogel containing water can be turned into water vapor utilizing the waste heat without affecting the thermogalvanic electricity generation. ${ }^{89}$ Hybridization of more than one energy scavenging technique with thermogalvanic cells is also possible with some minor modification to the device architecture. ${ }^{56,57} \mathrm{~A}$ hybrid photothermal electricity generator was fabricated with 


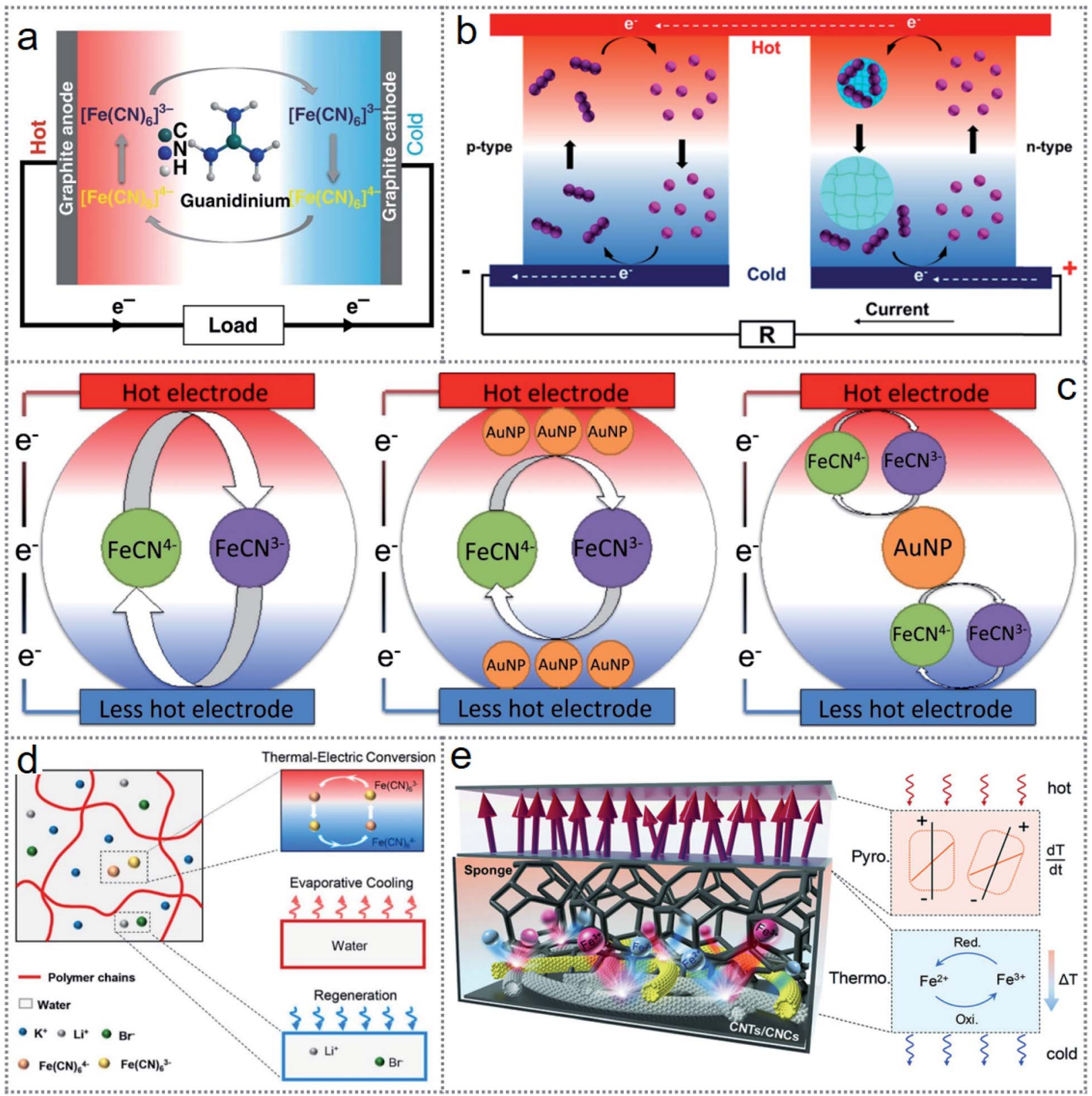

Fig. 6 Structure and working mechanism of redox-based thermogalvanic cells. (a) Schematic illustration of a typical thermogalvanic cell. (b) Operating principle of thermosensitive nanogel-induced $\mathrm{p}-\mathrm{n}$ conversion by $\mathrm{I}^{-} / \mathrm{I}_{3}{ }^{-}$redox couple. (c) Schematic of gel-based thermogalvanic cell (left side image), physically sandwiched AuNPs by the hydrogel (middle image), and discrete formation of AuNPs throughout the hydrogel of the cells. (d) Structure of smart thermogalvanic gel that scavenges heat energy and has evaporative cooling capability simultaneously. (e) Device architecture of the hybridized thermogalvanic and pyroelectric effect and working mechanism. Figures reproduced with permission from: (a) ref. 48, () 2018, Nature; (b) ref. 86, ( ) 2019, Elsevier; (c) ref. 88, ( ) 2019, Elsevier; (d) ref. 89, ( ) 2020, the American Chemical Society; and (e) ref. 56, () 2018, Wiley.

carbon nanotube (CNT)-based nanocomposites, which integrated thermogalvanic and pyroelectric power generation. ${ }^{56}$ The CNT-based nanocomposite, working as the solar heat absorber and excellent electrical/thermal conductive electrodes simultaneously, possessed a large electrochemically active large surface area. As shown in Fig. 6e, the upper part of the device having the solar heat absorber nanocomposites initiates the pyroelectricity generation, while the reticulate sponge containing electrolyte performs the thermogalvanic process. Thus, the compact device reduces the complexity and cost as an alternative to solar cells. Also, the device can work both inland and in water, increasing the reliability with feasible real-life applications. A similar concept of multitasking due to the flexibility of device architecture led to the fabrication of a solar-driven energy harvesting device with energy storage simultaneously. ${ }^{59}$ More reported works with their functional materials, performance-enhancing techniques, and related applications for redox-based thermogalvanic energy scavenging devices are summarised in Table 2 . 
Table 2 Summary of thermogalvanic redox-based energy scavenging devices with their performance-enhancing methods, functional materials, device outputs, and applications

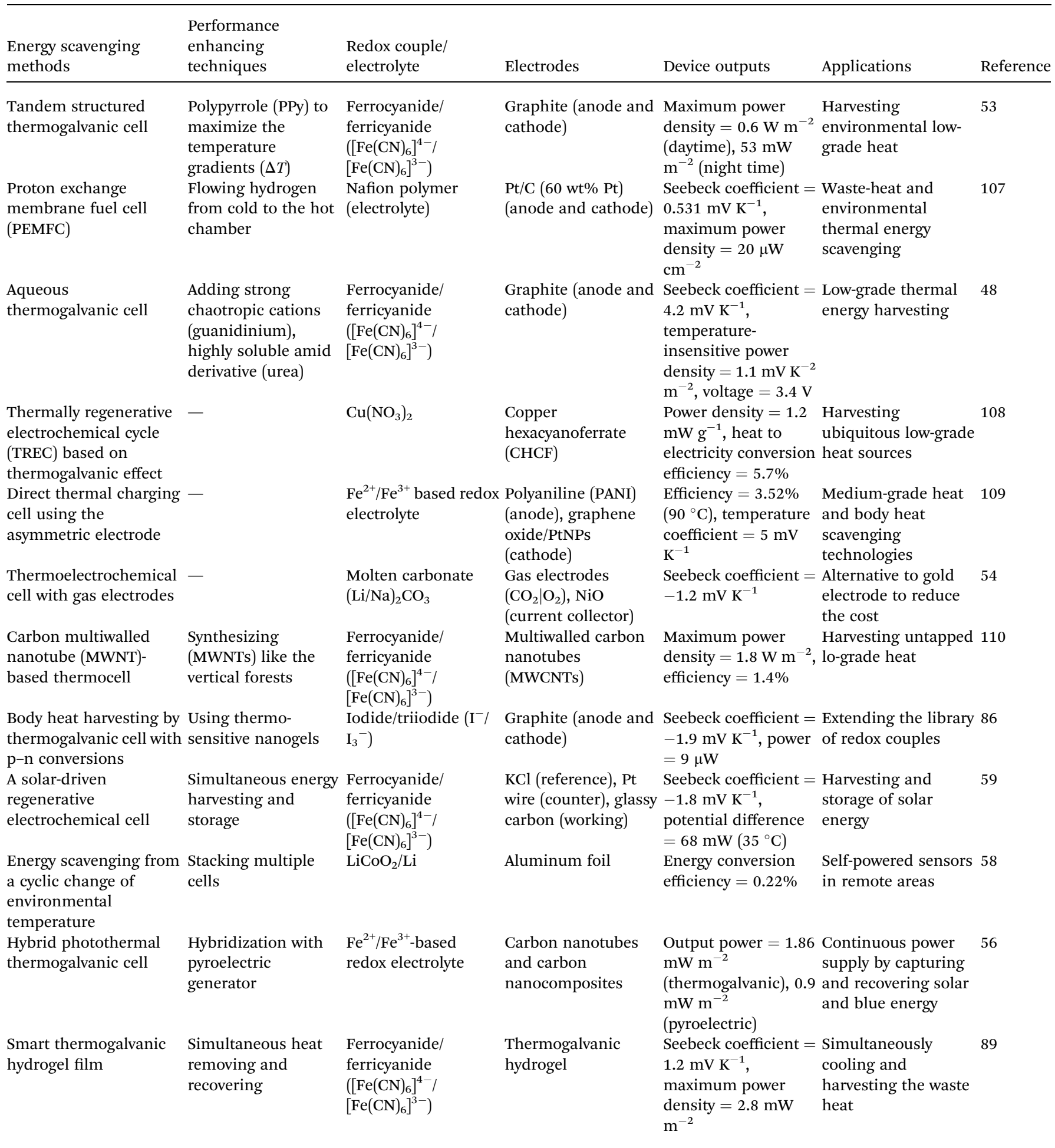

\subsection{Materials, structures, and mechanisms of photoelectrochemistry-based redox devices}

Energy scavenging through the oxidation-reduction reaction depends on the selected combination of materials and related thermodynamics and kinetics. In a photochemistry-based redox reaction, the driving force comes from the photon energy from light. The commonly investigated processes for energy scavenging are dye-sensitized solar cells (DSSCs), photocatalysis, and solar-powered redox cells (SPRCs). Considering that photosensitive metal electrodes play an important role in enhancing the photoelectrochemical effect, especially the anode (photoanodes), to enhance the device performances, the 
electrodes have been subjected to some modifications such as electrodeposited $\mathrm{Cu}_{2} \mathrm{O}$ layered $\mathrm{Au}$ (gold) particle-coated $\mathrm{TiO}_{2}$ nanorods were used for the fabrication of an Au-mediated $\mathrm{Cu}_{2} \mathrm{O}$-based $\mathrm{Z}$-scheme, where the SEM image is shown in Fig. 7a (left-sided upper image).${ }^{90}$ Also, $\mathrm{TiO}_{2}$-coated carbon fiber
(CF) electrode was uniformly coated with densely packed wrinkled $\mathrm{MoS}_{2}$ nanofilms, where the SEM image is presented in Fig. 7a (right-sided upper image). ${ }^{91}$ Besides, synthesizing novel and effective photocatalysts such as an $\mathrm{NiO} / \mathrm{Ag}_{3} \mathrm{PO}_{4} \mathrm{Z}$-scheme via ion-exchange deposition methods can extend the device
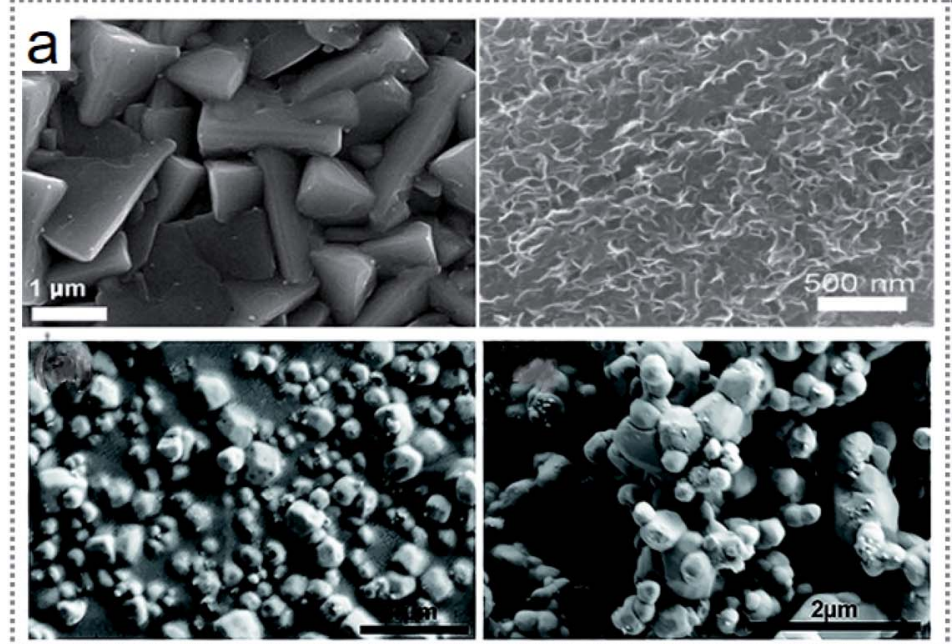

\section{C}
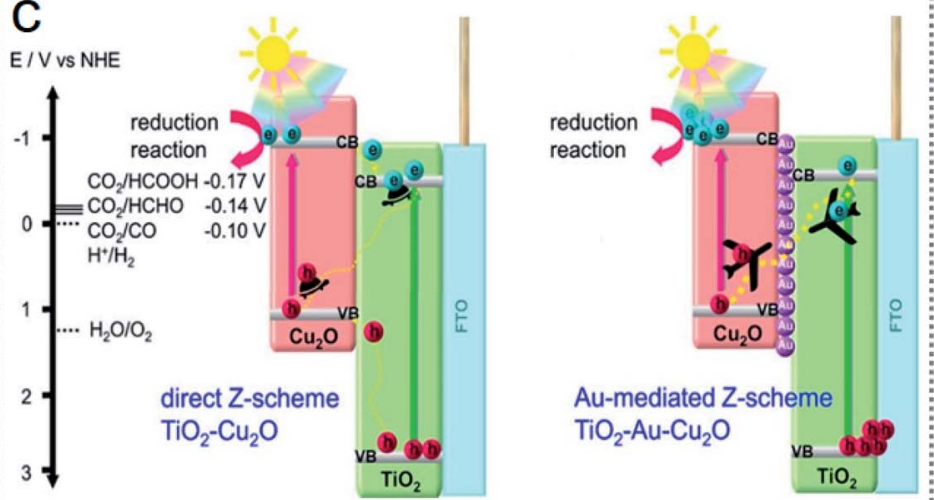

Au-mediated Z-scheme $\mathrm{TiO}_{2}-\mathrm{Au}-\mathrm{Cu}_{2} \mathrm{O}$ b

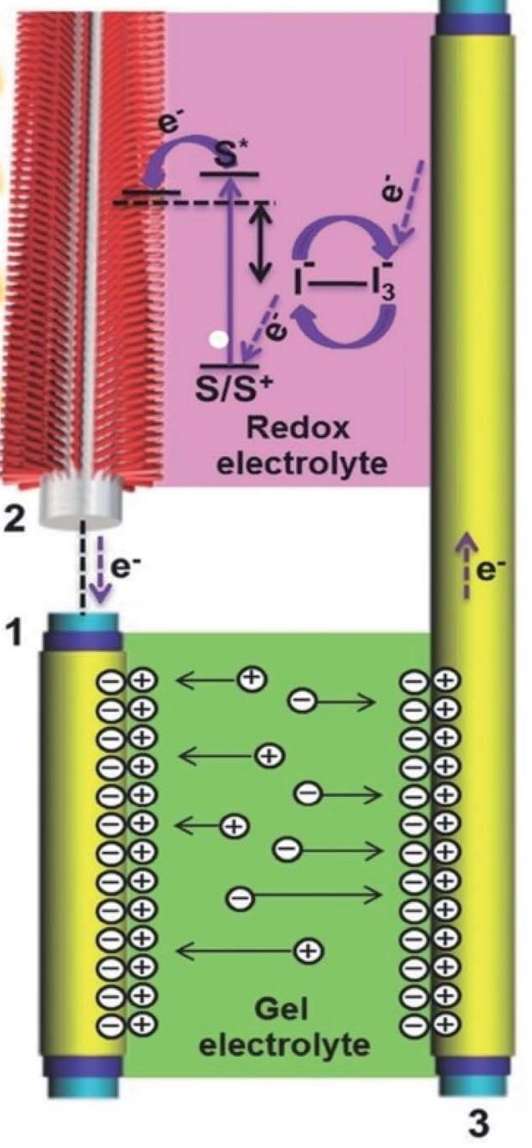

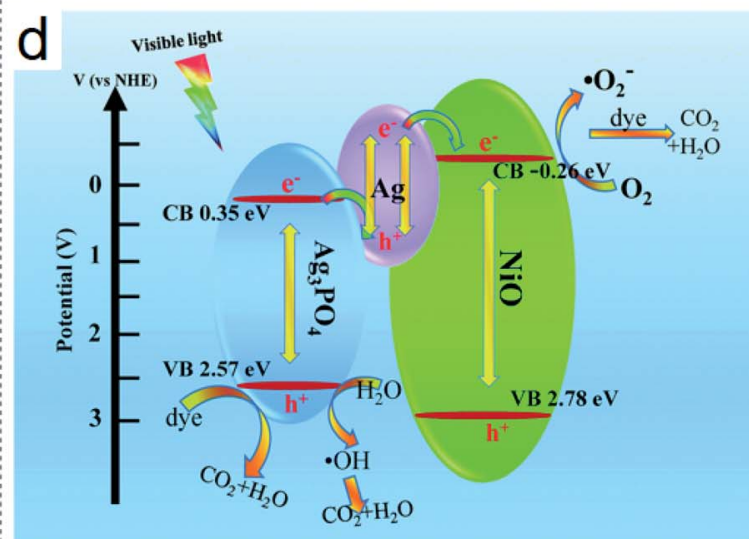

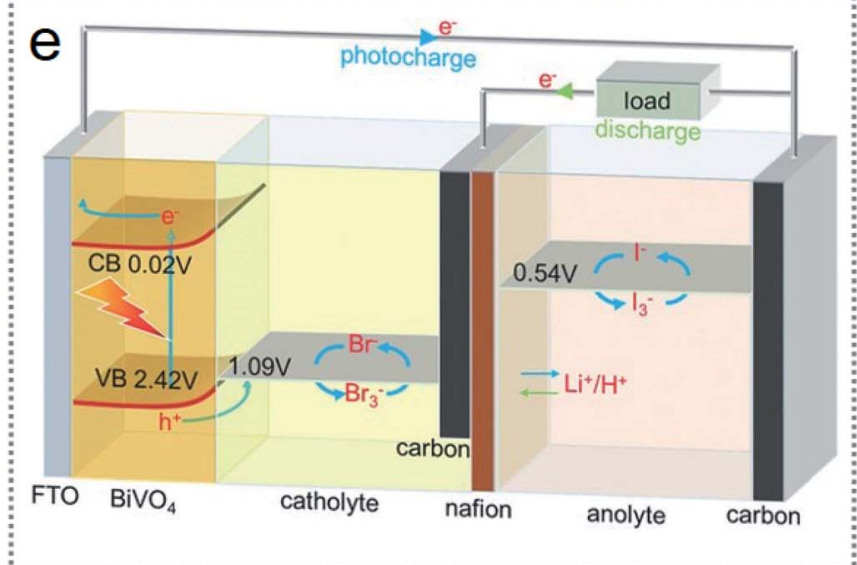

Fig. 7 Materials, structure, and operating principle of electrochemistry-based redox devices. (a) SEM image of Au particle-covered TiO ${ }_{2}$ nanorod with $\mathrm{Cu}_{2} \mathrm{O}$ layer (left side upper image), $\mathrm{TiO}_{2}$-coated carbon fiber coated with wrinkled $\mathrm{MoS}_{2}$ (right side upper figure), and $\mathrm{NiO} / \mathrm{Ag}_{3} \mathrm{PO}_{4}$ photocatalyst (bottom figures). (b) Schematic combination of DSCC and a fibrous supercapacitor (SC). (c) Charge transfer mechanism of Auembedded Z-scheme. (d) Illustration of the mechanism of the photocatalytic process. (e) Working mechanism of a solar-powered redox cell. Figures reproduced with permission from: (a) ref. 90-92, ( ) 2018, the American Chemical Society and 2020, the Royal Society of Chemistry; (b) ref. 91, (c) 2017, Wiley; (c) ref. 90, (c) 2018, the American Chemical Society; (d) ref. 92, (c 2020, the Royal Society of Chemistry; and (e) ref. 70, () 2018, Wiley. 
performances, where the SEM image photograph of the $\mathrm{NiO} /$ $\mathrm{Ag}_{3} \mathrm{PO}_{4}$ photocatalysts is depicted in Fig. 7a (lower row), indicating the irregular spherical shape of $\mathrm{Ag}_{3} \mathrm{PO}_{4}$ (left side image), while NiO has a polyhedron shape (right side image)..$^{92}$ By merging a DSSC (dye-sensitized solar cell) with a fibrous supercapacitor (SC) based on fibrous $\mathrm{MoS}_{2}$ electrodes, a selfpowered energy fiber was fabricated. ${ }^{91} \mathrm{An} \mathrm{MoS}_{2}$ nanofilm on $\mathrm{TiO}_{2}$ nanoparticle (NP)-coated carbon fiber (CF) (CF@TiO $\mathrm{MoS}_{2}$ ) electrode was used as a CE (counter electrode) for a DSSC and a cathode for SC, while as the anode of another SC, as illustrated in Fig. 7b. The dye-sensitized $\mathrm{TiO}_{2}$ nanoarray grown Tie wire is the working electrode of the DSSC, which is connected with the anode of the supercapacitor when it undergoes a charging state. When the device is under illumination, the dye molecules enter the excited state $\left(\mathrm{S}^{*}\right)$ from the ground $(\mathrm{S})$ (Fig. 7a), and the movement of free electrons towards the CB (conduction band) of $\mathrm{TiO}_{2}$ leads to the oxidation of the dye molecules $\left(\mathrm{S}^{*} \rightarrow \mathrm{S}^{+}\right)$. Then the excited electrons travel to the anode of the supercapacitor (SC) from the working electrode of the DSSC. The free electrons originate from the oxidation of the iodide ions $\left(\mathrm{I}^{-} \rightarrow \mathrm{I}_{3}{ }^{-}+\mathrm{e}^{-}\right)$reduced the dye molecules to the ground state simultaneously. Consequently, the diffusion of $\mathrm{I}_{3}{ }^{-}$ occurs at the $\mathrm{CF} @ \mathrm{TiO}_{2} @ \mathrm{MoS}_{2}$ counter electrode, where they are transformed into $\mathrm{I}^{-}$by the catalysis process of the ultrathin $\mathrm{MoS}_{2}$ nanofilm. Applying continuous irradiance, the flowing electrons from the working electrodes to the anode of the SC will remain spontaneous and electrical power will be stored in the SC continuously.

For high redox ability reduction applications, for enhancing the electron transport, some nanoparticles such as AuNPs can be used as charge transfer mediators for the improvement of the device output. The charge transfer mechanism of the Auembedded Z-scheme is illustrated in Fig. 7c with the consolidated effectiveness of the $\mathrm{Z}$-scheme with $\mathrm{Au}$ mediation. ${ }^{90}$ The accumulation of electrons and holes at $\mathrm{Cu}_{2} \mathrm{O}$ and $\mathrm{Ti}_{2} \mathrm{O}$ occurs due to the recombination of interfacial charge under light irradiation, indicating a high reduction and oxidation power from the SEM-EDS elemental mapping analysis for the $\mathrm{Au}$ mediated device. The extended photoelectrochemical performances of $\mathrm{Ti}_{2} \mathrm{O}-\mathrm{Au}-\mathrm{Cu}_{2} \mathrm{O}$ are obtained because of the overall improvement in electron kinetics, enhanced charge separation speed, and increased density of charge carriers in the electrolyte. The photocatalytic performance was further improved by coupling the semiconductor materials such as $\mathrm{NiO}$ with $\mathrm{Ag}_{3} \mathrm{PO}_{4}$ to form a unique and highly effective photocatalyst. ${ }^{92}$ The best output through the investigation was found at $5 \% \mathrm{NiO} / \mathrm{Ag}_{3} \mathrm{PO}_{4}$, and Fig. $7 d$ presents the mechanism for the superior performance of the photocatalytic process. Initially, the metallic surface containing Ag nanoparticles absorbs light, and then the absorbed photons separate the electrons and holes. ${ }^{93}$ Some light-induced holes and electrons are also produced by $\mathrm{NiO}$ and $\mathrm{Ag}_{3} \mathrm{PO}_{4}$ under visible light irradiance. The electrons of the AgNPs are rapidly transported to the $\mathrm{CB}$ of NiO and simultaneously form the $\mathrm{O}_{2}{ }^{-}$active compound in the system by reacting with $\mathrm{O}_{2}$. Simultaneously, the photogenerated electrons of $\mathrm{Ag}_{3} \mathrm{PO}_{4}$ move to the $\mathrm{Ag}$ nanoparticles, while the remaining holes are used for oxidizing the dye molecules. Thereby, due to the faster charge transportation between $\mathrm{NiO}$ and $\mathrm{Ag}_{3} \mathrm{PO}_{4}$, the efficiency and lifetime of $\mathrm{Ag} / \mathrm{NiO} / \mathrm{Ag}_{3} \mathrm{PO}_{4}$ increase significantly with excellent stability.

Another redox-based photoelectricity generating technique is solar-powered redox cells (SPRCs), which scavenge solar light to generate electricity and also store the generated electrical energy. The photoelectrodes drive the nonspontaneous reversible redox reaction in SPRCs, which can deliver power through the reverse reaction, achieving low-cost and effective energy harvesting technology and storage facility. An SPRC was fabricated using nanoporous $\mathrm{WO}_{3}$-coated $\mathrm{BiVO}_{4}$ (photoanode), aqueous $\mathrm{Br}_{3}{ }^{-} / \mathrm{Br}^{-}$(catholyte), and $\mathrm{I}_{3}{ }^{-} / \mathrm{I}^{-}$(anolyte), and its working mechanism is illustrated in Fig. 7e. ${ }^{70}$ A strong driving force is generated due to the higher positive potential of the valence band of $\mathrm{BiVO}_{4}$ than the redox potential of the $\mathrm{Br}_{3}{ }^{-} / \mathrm{Br}^{-}$ couple, leading to the oxidation of $\mathrm{Br}^{-}$by holes. Also, the more negative conduction band compared to the redox potential of $\mathrm{I}_{3}{ }^{-} / \mathrm{I}^{-}$works as the prime driving force for the reduction of $\mathrm{I}_{3}{ }^{-}$ by the excited electrons. Thus, the solar energy is stored through the overall redox reaction, which can be delivered to the external circuits again through the reverse redox reactions. Besides, in the case of artificial photosynthesis, solar-driven water-splitting techniques utilize photon energy to scavenge energy based on redox reactions. More reported photochemistry-based energy scavenging devices with functional materials are summarised in Table 3. However, there are some factors such as variation in solar irradiance, fluctuation in temperature, $\mathrm{pH}$ levels, and photocatalyst dosage that can affect the device output. Also, the crucial lower efficiency and costly fabrication are the main obstacles in the application of photochemistry-based energy scavenging techniques based on redox reactions.

\section{The performance and characteristics of redox-based energy scavenging devices}

The primary goal for energy scavenging by redox reactions is to develop an alternative to the conventional power supply, which suffers from environmental issues. Many energy scavenging devices have been fabricated to produce green energy for some low-power electronic sensors and devices, where the efficiency is not a crucial factor to replace the conventional grid supply. Although the overall efficiencies are still very low, in the near future, the mass production of power is possible through extensive research and technological advancement in this area. The lifetime and stable operation of the fabricated devices are also very important for practical applications. Here, the performances of recently reported works will be discussed from a real-life perspective with the requirement of output power for nanosensors and nanosystems.

\subsection{Performance of electrochemistry-based redox devices}

Electrochemistry-based redox reaction devices suffer from a lack of efficiency, which is not significant in most cases given that the purpose of the device is related to much more important matters. The multifunction scope such as waste 
Table 3 Summary of photoelectrochemical redox-based energy scavenging devices with their performance-enhancing methods, functional materials, device outputs, and applications

\begin{tabular}{ll}
\hline Energy scavenging & $\begin{array}{l}\text { Performance } \\
\text { enhancing } \\
\text { methods }\end{array}$ \\
techniques
\end{tabular}

Solar power redox cell -
Redox couple/ electrolyte

$\mathrm{Br}_{2} / \mathrm{Br}^{-}, \mathrm{I}_{3}^{-} / \mathrm{I}^{-}$

\author{
Electrodes
}

Carbon with rutile-
phase $\mathrm{TiO}_{2}$

phase $\mathrm{TiO}_{2}$ photoanode (cathode) and carbon electrode (anode) Fluorine-doped tin oxide (FTO) (photoanode), carbon $=1.25 \%$, average casted tin foil (cathode)

A self-powered redox $\mathrm{WO}_{3}$ decorated $\mathrm{ViBO}_{4} \mathrm{Br}_{2} / \mathrm{Br}^{-}$(catholyte), cell (SPRC) based on photoanode $\quad \mathrm{I}_{3}{ }^{-} / \mathrm{I}^{-}$(anolyte) single-photocatalysis

\begin{abstract}
A dye-sensitized solar Applying ZnO cell (DSSC) nanoparticles into the electrolyte

A dye-sensitized solar Using $\mathrm{CoSe}_{2}$ / cell (DSSC)

MWCNTs as the counter electrode
\end{abstract}

$\begin{array}{ll}\text { A bio-sensitized solar } & \text { Integrating } \\ \text { cell (BSSC) } & \text { photosensitive } \\ & \text { protein } \\ & \text { Bacteriorhodopsin } \\ & \text { (BR) with } \mathrm{TiO}_{2} \\ & \text { Employing } \\ \text { Tandem p-n } & \text { Coumarin6 (C6) dye } \\ \text { photoelectrochemical } & \text { with CuCrO } \\ \text { cell } & \text { semiconductor }\end{array}$

A solid-state dye-

sensitized

photoelectrochemical

cell (DS-PEC)

Composite electrode- Growing $\mathrm{MoS}_{2}$ based DSSC nanofilms on $\mathrm{TiO}_{2}$ nanoparticle-coated $\mathrm{CF}$

Photoelectrochemical Using ZCS modified $0.35 \mathrm{M} \mathrm{Na}_{2} \mathrm{SO}_{3}+$ cell $\quad \mathrm{TiO}_{2}$ nanotube arrays $0.25 \mathrm{M} \mathrm{Na}_{2} \mathrm{~S}$

( $\mathrm{TiO}_{2}$-NTAs) (electrolyte)

$\mathrm{I}^{-} / \mathrm{I}_{3}{ }^{-}$(redox couple) BR integrated $\mathrm{TiO}_{2}$ and acetamide gel (photoanode), electrolyte platinum (Pt) (photocathode)

$\mathrm{I}^{-} / \mathrm{I}_{3}{ }^{-}$(redox couple) p-type C6 anchored $\mathrm{CuCrO}_{2}$ (photocathode), ntype $\mathrm{TiO}_{2}$ (photoanode) Phenoxazine (PZT) $\quad \mathrm{TiO}_{2}$ photoanode substituted DS-2 and ORS
$\mathrm{I}^{-} / \mathrm{I}_{3}{ }^{-}$(redox couple) $\mathrm{CF} @ \mathrm{TiO}_{2} @ \mathrm{MoS}_{2}$ (counter) and $\mathrm{TiO}_{2}$ (working)

TiO-NTAs/ZCS

(photoanode), tin foil photocurrent density

(anode), Pt (cathode) $=10.95 \mathrm{~mA} \mathrm{~cm}^{-2}$ at

$1.23 \mathrm{~V}$, optimum efficiency $=4.54 \%$

Au mediated Z- $\quad$ Embedded Au scheme based nanoparticles photoelectrochemical accelerate the cell electron transfer Photoelectrochemical cell-based water splitting

\section{Solar energy to} chemical energy through

photosynthesis Bioelectrochemical systems (BES)
$0.5 \mathrm{M} \mathrm{Na}_{2} \mathrm{SO}_{4}$ bubbled with $\mathrm{CO}_{2}$ or $\mathrm{N}_{2}$

$1 \mathrm{M} \mathrm{KOH}, 0.5 \mathrm{M}$ $\mathrm{H}_{2} \mathrm{SO}_{4}$ (electrolyte)
$\mathrm{TiO}_{2}-\mathrm{Au}-\mathrm{Cu}_{2} \mathrm{O}$ Photocurrent density (photocathode), $\mathrm{TiO}_{2},=-1.82 \mathrm{~mA} \mathrm{~cm}^{-2}$ and $\mathrm{TiO}_{2}-\mathrm{Au}$ (photoanode) hydrogen evolving $\mathrm{p}^{-} \mathrm{mA} \mathrm{cm}{ }^{-2}$, voltage $=$ based on Si photocathode

Carbon felt

Solar to fuel energy
Oxygen evolving n-Si Generated conversion

portable electronic

photoanode, $\quad$ photocurrent $=10 \quad$ performance PECs

$0.87 \mathrm{~V}$ (anode), $0.42 \mathrm{~V}$ nanocrystalline (cathode) electrocatalysts

Carbon gauze Output current $=10$ - Generating bioelectricity from the photosynthetic biological organisms Maximum Coulomb Solar energy Exogenous quinone Chlorella Vulgaris,
as electrons mediator Rhodopseudomonas palustris (bacteria) (working), titanium wire (counter), efficiency $42.12 \%$ and harvesting peak current $12.2 \mathrm{~mA}$
91 
Table 3 (Contd.)

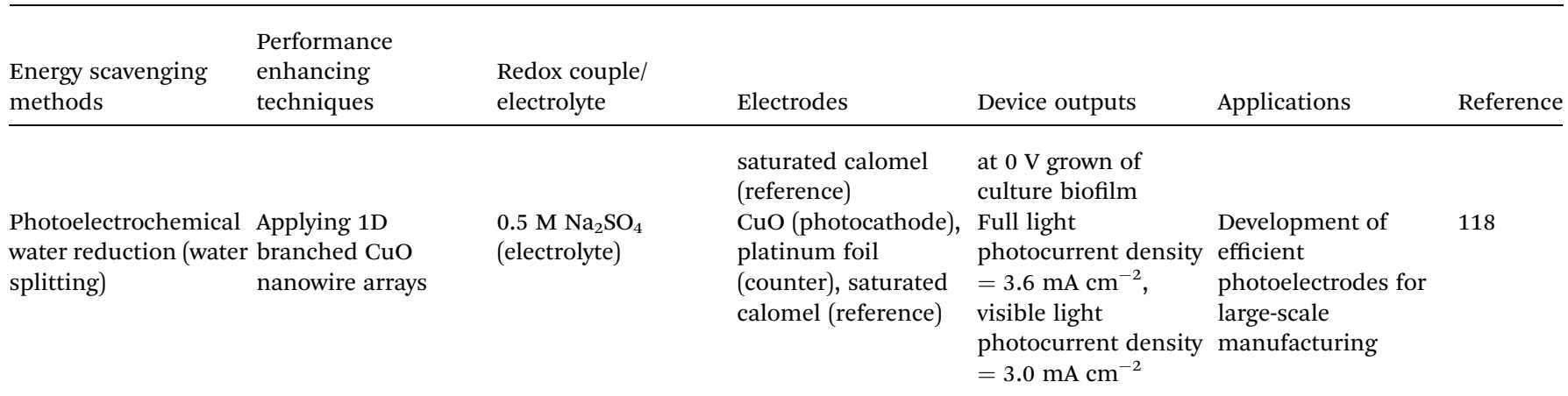

management ${ }^{29}$ and desalination of saltwater ${ }^{45}$ with additional features such as soft, stretchable, and wearable nature ${ }^{\mathbf{8 1}}$ make these devices more important to investigate. A self-powered floating micro-robot was fabricated, which could produce an electrical potential of $1.38 \mathrm{~V}$ and output current of $0.025 \mathrm{~A}$ by the redox reaction between water and hydrophobic copper $(\mathrm{Cu})$ and magnesium $(\mathrm{Mg})$ wires without any other support. ${ }^{30}$ Fig. 8a shows the output current (left-side graph) and the variation in the generated current and power related to the applied load (right-side graph). Most importantly, the generated power was sufficient for the movement of $1.45 \mathrm{~cm} \mathrm{~s}^{-1}$ by adding a motor with a shape-memory alloy. An extended output voltage of $3.3 \mathrm{~V}$ was obtained with the implementation of a power management system, which was sufficient to power a temperature-sensing device and an LED bulb. Fig. 8b presents the output power from a sweat-harvesting device (Fig. 5c), where the single-wall carbon nanotube-coated Cu (SWCNT@Cu) electrode gave the maximum output power of $2.2 \mathrm{~mW}$. The stability of these devices is good enough for practical applications in some lowpowered electronics.

An electrochemical generator (ECG) was introduced with PB (Prussian blue) active coatings on the surface of polyester carbon nanotubes to harvest energy and sense continuous motion simultaneously. ${ }^{35}$ This fiber-based ECG is an excellent example of the coupling of mechanical-electrochemical energy, which can be used in many practical applications. The fabricated ECG was inserted into a fabric with a gel electrolyte. Fig. 8c shows the practical use of the fabric on a human arm (leftmost image) with the rotation at several angles to sense the elbow position by the ECG response in different angles (rightmost graph). The output from the ECG was almost identical for the liquid electrolyte (control) and gel electrolyte (fabric) (middle graph), indicating the stable operation of the device. ${ }^{35}$ Hybridization of different energy harvesting techniques is being investigated to obtain better performances. The hybridization of an energy scavenging module was introduced with the integration of a triboelectric nanogenerator and glucose fuel cell (Fig. 5f), which can be used for in vivo applications. ${ }^{39}$ The device was capable of lighting a "BINN"-shaped LED array, as shown in Fig. 8d (leftmost image). The middle and rightmost graphs of Fig. $8 \mathrm{~d}$ represent the output voltage and current variations by applying distinct loading times, where it is clear that the voltage increased to $0.6 \mathrm{~V}$ after three times loading (middle graph of Fig. 8d). ${ }^{39}$ Given that the maximum current was also found after three times of loading, then it is more effective for the fabrication of the hybrid device after three times loading.

For more convenient hybridization, a hybrid textile device was fabricated with a biofuel cell (BFC) and a supercapacitor (SC) based on sweat harvesting from the human body. ${ }^{26}$ The fabricated BFC device harvests the bioenergy from sweat and stores the generated power simultaneously as a self-charging supercapacitor. The maximum generated voltage of $0.49 \mathrm{~V}$ was obtained from the BFC, while the optimum power density of 252 $\mu \mathrm{W} \mathrm{cm}^{-2}$ was found at $0.28 \mathrm{~V}$. The stable operation of the proposed BFC is demonstrated in Fig. 8e, where the corresponding power density graphs of the device response before (black dashed lines) and after (pink lines) 100 times of bending ( $1^{\text {st }}$ figure with the bottom graph), twisting ( $2^{\text {nd }}$ figure with the bottom graph), and $20 \%$ stretching ( ${ }^{\text {rd }}$ figure with the bottom graph) are shown. Fig. 8f depicts a comparative view of the device performance in the case of power density of the electrochemical energy generator (ECG) with the relative human motion. ${ }^{35}$ It is clear from the figure that in the case of very low motion, the performance of the ECG devices is comparatively better than that of the piezoelectric energy generator (PEG), and triboelectric energy generator (TEG), which indicates the optimistic future of electrochemistry-based energy scavenging techniques. More reported works with the redox-based energy scavenging devices based on electrochemistry with their output performances are summarised in Table 1.

\subsection{Performances of thermogalvanic effect-based redox devices}

Thermogalvanic effects in energy scavenging are techniques that are increasing extensively given that they can directly convert the surrounding waste heat from every possible source into electrical power without any emission of pollutants and material consumption. However, thermogalvanic cells have a relatively low efficiency with low output power, although the recent research advancement in novel electrode materials, effective electrolyte, and redox couples, extensive studies on redox chemistry, efficient device architecture have increased the 

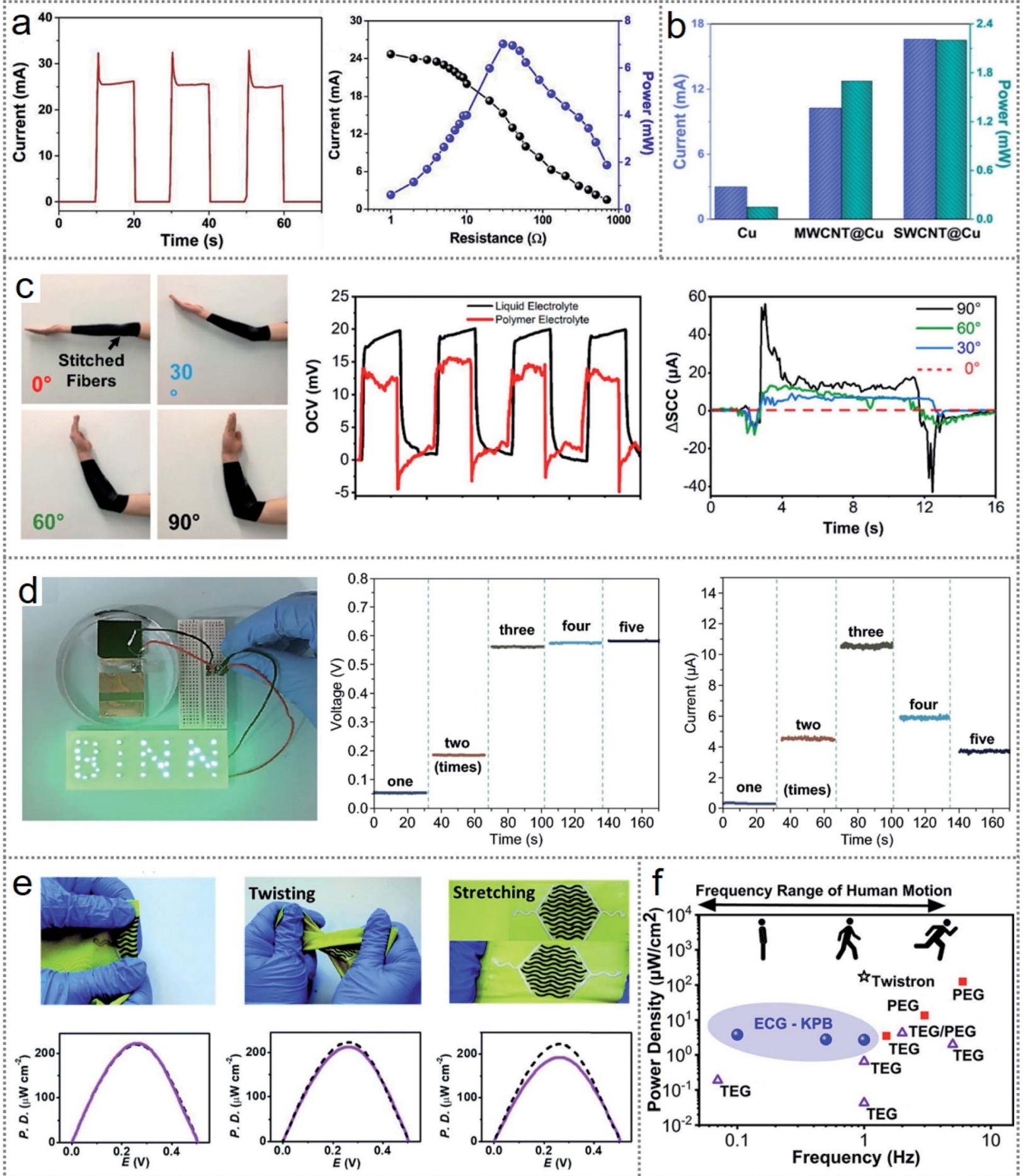

Fig. 8 Performances of electrochemical redox devices. (a) Output current (left side graph) and variation of current and power according to the applied load to the microrobot (right side graph). (b) Performance comparison of Cu, SWCNT, and MWCNT electrodes. (c) Output performances of the fabric-based wearable electrochemical generator during human arm rotation. (d) Voltage and current variation under different loading times of the fabricated device. (e) Responses of the textile-based device in normal, twisting, and stretching conditions. (f) Comparative performances according to the output power density under human motion. Figures reproduced with permission from: (a) ref. 30, (c) 2019, Elsevier; (b) ref. 25, @ 2020, the American Chemical Society; (c), (f) ref. 35, @ 2020, the American Chemical Society; (d) ref. 36, @ 2020, Springer; and (e) ref. 26, ๔ 2018, the Royal Society of Chemistry.

cell performances from a commercial perspective. Nevertheless, the applicability of thermogalvanic cells has major challenges because of the fluctuations in ambient temperature, lower heat during the night, and uncertainty in solar heat due to weather changes. Accordingly, the flexibility of entropy-driven redox reactions to select proper materials with appropriate 
concentration and device structure can overcome all these limitations. ${ }^{94}$ For all-day energy generation during both night and day, a stacking structured device was fabricated (Fig. 3a), providing a daytime output power of $0.6 \mathrm{~W} \mathrm{~m}^{-2}$ with a nighttime power of $53 \mathrm{~mW} \mathrm{~m} \mathrm{~m}^{-2} \cdot{ }^{3}$ The performance of the thermogalvanic cell increased by using polypyrrole (PPy) as a phase-changing material (PPy-PCM) given that it is a good absorber and radiator. Fig. 9a shows the device outputs with no PCM, G(graphite)-PCM and PPy-PCM during both daytime (leftmost graph) and night-time (middle graph), where the
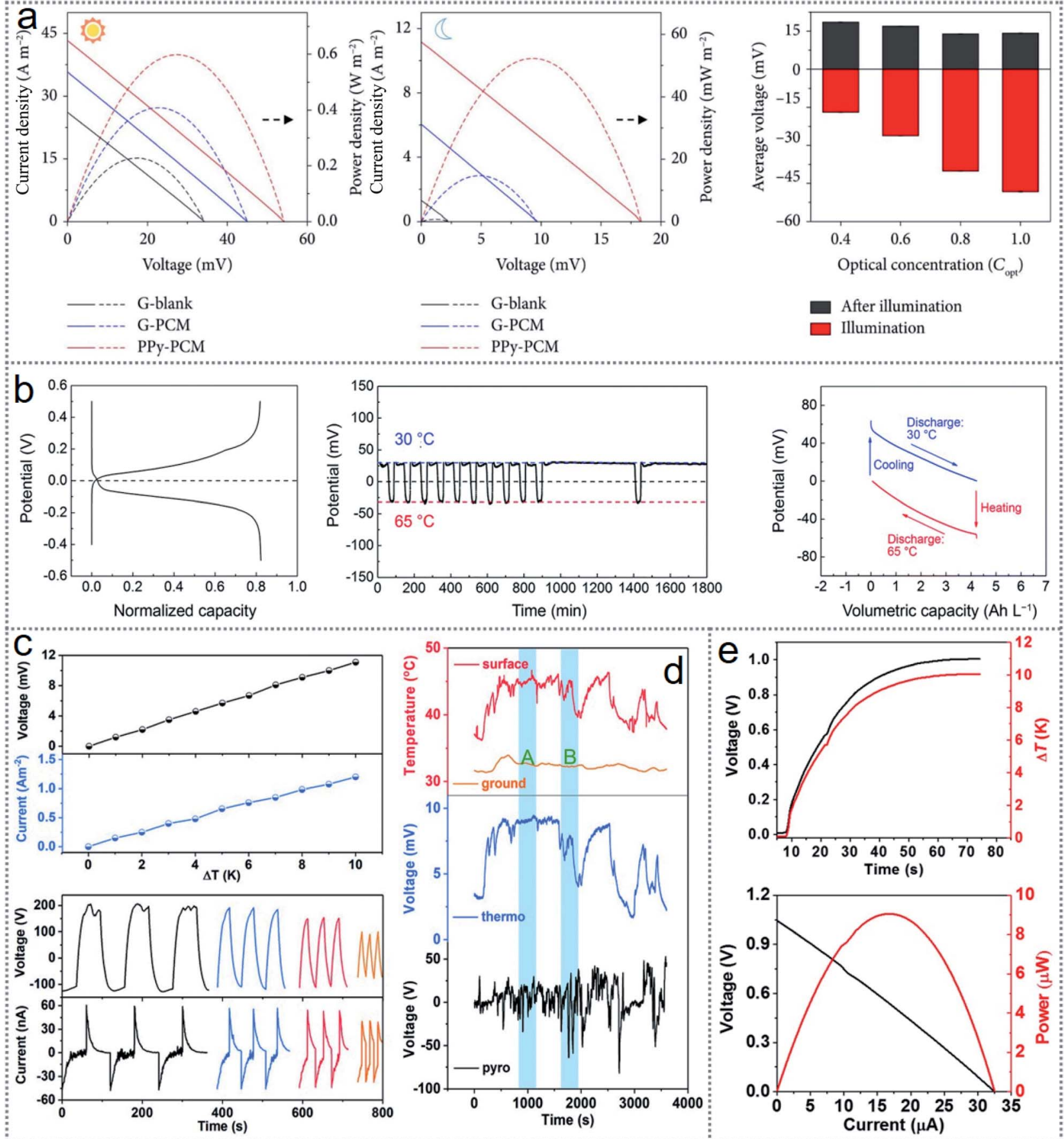

Fig. 9 Performances of thermogalvanic devices. (a) Outputs of the stacked device with and without polypyrrole (PPy) as the phase-changing material (PPy-PCM) during the day and night-time. (b) Solar heat scavenging performances of the thermogalvanic cell. (c) Effect of temperature gradients (upper graph) and cyclical irradiance (bottom graph) on the photothermal pyroelectric generator. (d) Performance of the device in some adverse conditions such as under temperature fluctuations and windy weather. (e) Output voltage (upper graph) with a variation in the temperature gradient and maximum voltage and current (bottom graph) of the hybrid device. Figures reproduced with permission from: (a) ref. 53, (c) 2019, Science Partner Journal; (b) ref. 59, (c) 2019, the Royal Society of Chemistry; (c) and (d) ref. 56, (c) 2018 Wiley; and (e) ref. 86, (c) 2019, Elsevier. 
significance of using PCM is clarified for optimum performance. The average open-circuit voltage $\left(V_{\mathrm{oc}}\right)$ with various concentrations of light for the device is illustrated in Fig. 9a (rightmost graph), which reveals the proportional increase in the voltage with an increase in the light concentration during illumination, whereas no observable changes were found during the post-illumination periods because of the same capacity of PCM to store thermal energy.

Among waste heat sources such as industrial waste heat, automobiles, and human body heat, solar heat is the most significant sustainable source. A thermogalvanic cell that scavenges solar heat through redox reaction and stores the harvested energy was fabricated with great energy converting efficiency of up to $1.23 \%$ (11.9\% of the Carnot efficiency). ${ }^{59}$ The electrochemical performance of the cell is presented in Fig. 9b, where the typical charge-discharge behavior of the fabricated cell shows the intersection of the charging and discharging curves at approximately $0 \mathrm{~V}\left(1^{\text {st }}\right.$ graph), which confirms the regenerative electrochemical working cycles. The stable operation of the device was also positive as the output voltage maintained an almost identical $0.030 \mathrm{~V}$ at $30{ }^{\circ} \mathrm{C}$, and $-0.032 \mathrm{~V}$ at $65{ }^{\circ} \mathrm{C}\left(2^{\text {nd }}\right.$ graph $)$ without considerable fluctuations for $1800 \mathrm{~min}$. Also, the voltage-capacity results under $200 \mu \mathrm{A} \mathrm{cm}^{-2}$ $\left(3^{\text {rd }}\right.$ graph) revealed an excellent galvanostatic discharge profile at this temperature gradient level among the reported works. ${ }^{59}$ Considering that the integration of charge storage makes the device more reliable for practical applications, similarly, hybridization of more scavenging techniques increases the device performance. To overcome the unpredictable ambient conditions, a photothermal pyroelectric generator and thermogalvanic cell were hybridized (Fig. 6e) for continuous energy scavenging by utilizing solar and surrounding waste heat. ${ }^{56}$ The device outputs were closely related to the temperature gradients $(\Delta T)$, where Fig. 9c (upper graph) shows the increasing voltage and current with an increase in $\Delta T$, and slightly depending on the cyclical irradiation times, as shown in Fig. 9c (bottom graph), where there is a slight decrease in the voltage and current with an increase in the number of cycles. The adaptation to the adverse conditions of fluctuating temperature and windy weather by the hybrid device is illustrated in Fig. 9d, where the outputs were recorded in the ground, water, and night-time. The result shows a slight erratic stability in the ' $\mathrm{B}$ ' period compared to the stable operation during the ' $A$ ' periods according to the temperature. The reason for the unstable result of thermoelectric power generation is the fluctuating irradiance level and windy weather, where the pyroelectric generation was more stable.

Considering that the power conversion efficiency of thermogalvanic cells is low, with the advancement of electrodes, electrolytes, and redox couples, many novel concepts such as hybridization and multicell systems have been introduced to achieve higher outputs. Enabling p-n conversion in the redox couple $\left(\mathrm{I}^{-} / \mathrm{I}_{3}{ }^{-}\right)$(Fig. $\left.6 \mathrm{~b}\right)$ is a new approach for scavenging body heat. ${ }^{86}$ The fabricated device has series-connected alternating units of $\mathrm{I}^{-} / \mathrm{I}_{3}{ }^{-}$(p-type) and $\mathrm{I}^{-} / \mathrm{I}_{3}{ }^{-}$(n-type). Fig. 9e presents the generated voltage with a variation in the temperature gradient (upper graph), where the optimum voltage and current (bottom graph) of $1 \mathrm{~V}$ and $32 \mu \mathrm{A}$ were derived at $5{ }^{\circ} \mathrm{C}$ (surrounding temperature), respectively. Many wearable electronics can be operated with this level of output without any external power supply. Many new materials with novel device architectures are being investigated by the scientific community for highly effective, low cost, and stable performances from thermogalvanic devices. More reported works with their functional materials and performances are summarized in Table 2.

\subsection{Performances of photoelectrochemistry-based redox devices}

In photoelectrochemistry, electric power is generated through redox reactions at the photoanode, where the driving force comes from the photon energy. Many photoelectrochemical energy scavenging modes including dye-sensitized solar cells (DSSCs), solar-powered redox cells (SPRCs), photocatalysis, photosynthesis, and water-splitting are gaining much attention from the scientific community. ${ }^{95}$ Through the extensive investigation of DSSCs in recent decades, the highest energy conversion efficiency of $14.3 \%$ has been recorded. ${ }^{96}$ Generally, in DSSCs, aqueous electrolytes are used as the charge transporting medium, but a quasi-solid bi-layered electrolyte was introduced in a DSSC (Fig. 4b) to enhance the device performance. ${ }^{67}$ The superior performances of the quasi-solid device compared to that of the liquid-state device is clear from Fig. 10a (both graph), indicating the better current density, electrical potential, and efficiency of the quasi-solid-state DSSC over the liquid-state DSSC. An ultra-high efficient DSSC was fabricated by using a fibrous (carbon fiber) electrode coated with $\mathrm{MoS}_{2}$ nanofilms (Fig. 7b), facilitating energy storage simultaneously. ${ }^{\mathbf{1 1}}$ The charging/discharging behavior was studied in three modes, i.e., galvanostatic charging/discharging (Mode I) (without illumination) (black lines), photo charging/galvanostatic discharging (Mode II) (red lines), and photo-assisted charging/ galvanostatic discharging (Mode III) (blue lines), as illustrated in Fig. 10b (upper graph). Mode II and Mode III were faster and more effective than the galvanostatic charging/discharging given that Mode I needed $37 \mathrm{~s}$ to reach $0.8 \mathrm{~V}$, whereas Mode II and Mode III only took 7 and $8 \mathrm{~s}$ to reach $0.65-0.7 \mathrm{~V}$, respectively. The efficiency of the energy conversion from photochemical to electrical is plotted related to the photo-charging time in Fig. 10b (bottom graph), which showed an increase in efficiency up to $1.8 \%$ within $2 \mathrm{~s}$ and then it started decreasing.

Artificial photosynthesis is an approach inspired by the natural photo-conversion into chemical energy, where the photon energy is transferred into chemical energy as fuels, for example water is turned into $\mathrm{O}_{2}, \mathrm{H}_{2}$, and carbohydrates. Photoelectrochemical cells are externally biased for oxidation and reduction reactions to construct artificial photosynthesis by combining the photocatalytic process with electrochemical processes. ${ }^{90}$ The Z-scheme charge transfer system is designed based on the photosynthesis mechanism in green plants, where two separate semiconductor nanostructures split water into chemical fuels by electron-transporting redox reactions at the interface between the two semiconductors. ${ }^{97,98}$ In the Z-scheme process, charge separation is crucial for the reduction reaction, 

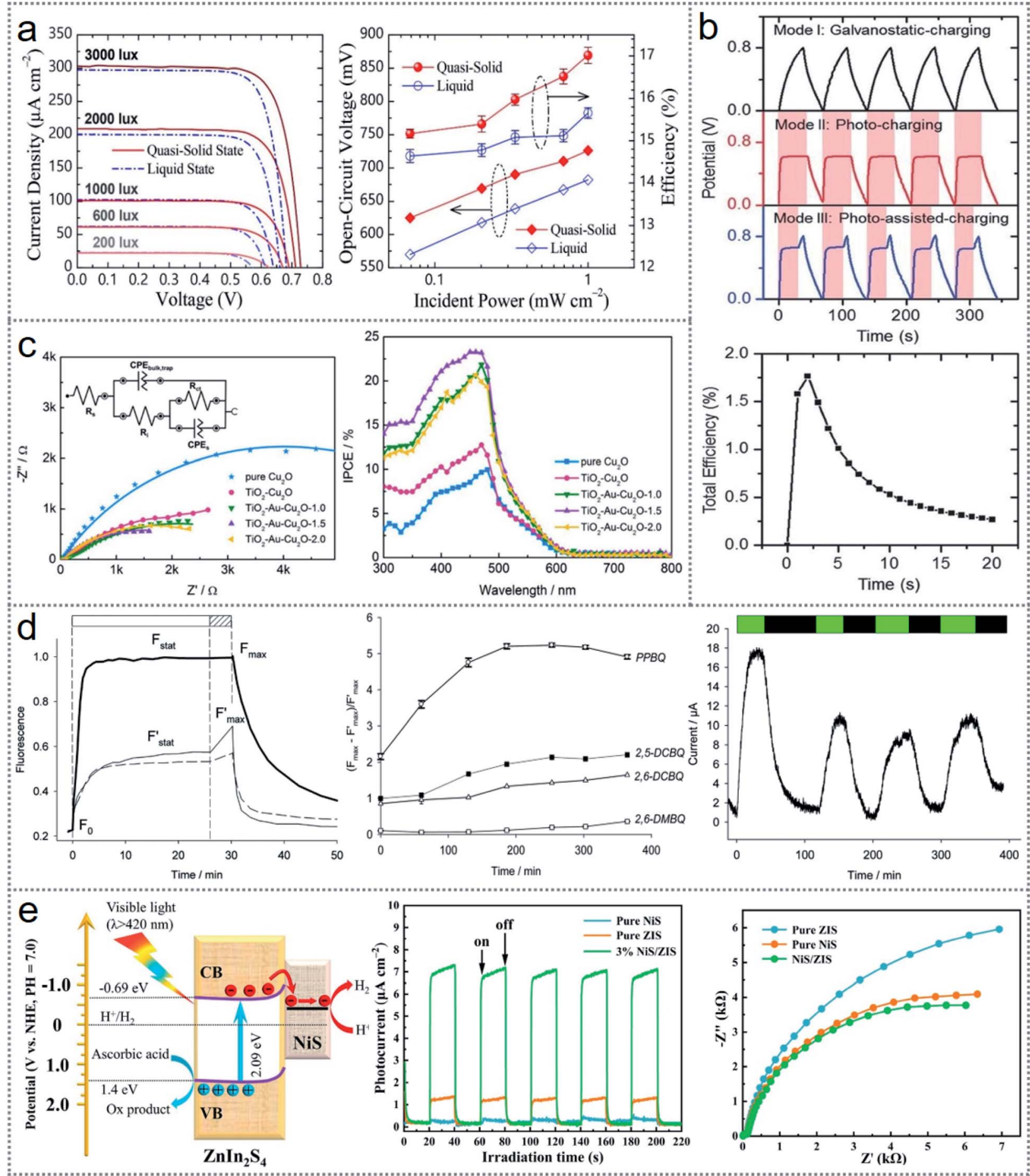

Fig. 10 Performances of photoelectrochemical-based redox devices. (a) Enhancement in the performance of the quasi-solid device compared

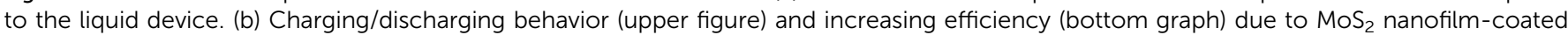
electrode. (c) Effectiveness of AuNPs in the device performance illustrated by the Nyquist plot $\left(1^{\text {st }}\right.$ graph) and photon conversion efficiency ( ${ }^{\text {nd }}$ graph). (d) Performance of the device in bioelectricity generation through the photosynthesis process. (e) Charge transport improving mechanism ( $1^{\text {st }}$ image) and device performance enhancement $\left(2^{\text {nd }}\right.$ and $3^{\text {rd }}$ graph) using $3 \%$ NiS/ZIS. Figures reproduced with permission from: (a) ref. 67, (c) 2021, Elsevier; (b) ref. 91, (c) 2017, Wiley; (c) ref. 90, (c) 2018, the American Chemical Society; (d) ref. 99, (c) 2018, the Royal Society of Chemistry; and (e) ref. 100, (c) 2021, Elsevier.

which is accelerated by using some electron transferring mediator (electron transfer bridge) to increase the device effectiveness. $\mathrm{A} \mathrm{Cu}_{2} \mathrm{O}$-based Z-scheme with $\mathrm{Au}$ (gold) mediator was introduced, where a $\mathrm{TiO}_{2}-\mathrm{Au}$-supported $\mathrm{Cu}_{2} \mathrm{O}$ heterostructure was used as the photocathode. ${ }^{90}$ The photo-excited electrons were transferred from $\mathrm{TiO}_{2}$ to $\mathrm{Cu}_{2} \mathrm{O}$ through the $\mathrm{Au}$ 
nanoparticles, making the whole system faster. The effectiveness of AuNPs is clear from Fig. 10c $\left(1^{\text {st }}\right.$ graph), where the Nyquist plot of the comparison among the pure $\mathrm{Cu}_{2} \mathrm{O}, \mathrm{TiO}_{2}-$ $\mathrm{Cu}_{2} \mathrm{O}$, and three $\mathrm{TiO}_{2}-\mathrm{Au}-\mathrm{Cu}_{2} \mathrm{O}$ electrodes are shown. The larger semicircle spectrum represents higher transfer resistance and the compressed semicircles for $\mathrm{TiO}_{2}-\mathrm{Cu}_{2} \mathrm{O}$ and $\mathrm{TiO}_{2}-\mathrm{Au}-$ $\mathrm{Cu}_{2} \mathrm{O}$ indicate the improved electron transfer kinetics in the $\mathrm{Z}$ scheme process. The curve of IPCE (incident photon to current conversion efficiency) in the device illustrated in Fig. 10c $\left(2^{\text {nd }}\right.$ graph) suggests the superiority of $\mathrm{TiO}_{2}-\mathrm{Au}-\mathrm{Cu}_{2} \mathrm{O}$ over the $\mathrm{Cu}_{2} \mathrm{O}$ and $\mathrm{TiO}_{2}-\mathrm{Cu}_{2} \mathrm{O} .^{90}$

Besides the Z-scheme, solar energy can be scavenged with some living organisms such as plants, bacteria and algae through the photosynthesis process to generate bioelectricity. ${ }^{\mathbf{9 9}}$ An investigation on this was carried out with a suspension of green algae (Chlamydomonas reinhardtii) in exogenous quinones redox mediators (Fig. 4d). ${ }^{99}$ The added exogenous mediators increased the fluorescence quenching, as shown in Fig. 10d $\left(1^{\text {st }}\right.$ graph), where the thick solid black line represents the quenching without the redox mediators, and thin black line (instantaneous) and black dashed line (after 3 hours) represent the enhanced fluorescence quenching with time. The quenching characteristics of different exogenous quinones as a function of the incubation period are shown in Fig. 10d ( $2^{\text {nd }}$ graph), indicating an increase in fluorescence with the incubation of quinones. However, the generated photocurrent depends on the quenching efficiency, where the output current behavior illustrated in Fig. 10d ( $3^{\text {rd }}$ graph) shows that the quenching kinetics is only affected the current magnitude in the first two pulses. This suggests that the saturation level of the quenching kinetics after the initial pulse gives a stabilized output current through the photosynthesis process. Photocatalytic water splitting by solar light is a promising technique for the production of chemical fuel. The boosted $\mathrm{H}_{2}$ production using semiconductor photocatalysis through improved charge separation and redox reaction was investigated. ${ }^{\mathbf{1 0 0}}$ Here, ultra-thin $\beta$-NiS nanosheets were placed on $\mathrm{ZnIn}_{2} \mathrm{~S}_{4}$ nanosheets to form a heterostructure junction. The mechanism of the improved charge separation through redox reaction is illustrated in Fig. 10e ( $1^{\text {st }}$ image $)$, where the photon-activated electrons in the $\mathrm{CB}$ of $\mathrm{ZnIn}_{2} \mathrm{~S}_{4}$ quickly move to the NiS surface, which accelerates the separation of the light-induced electrons-holes pairs of $\mathrm{ZnIn}_{2} \mathrm{~S}_{4}$, leading to a higher rate of $\mathrm{H}_{2}$ production. Thus, the Nisdeposited $\mathrm{ZnIn}_{2} \mathrm{~S}_{4}$ works as an electron trapping surface for faster carrier separation, enhancing the $\mathrm{H}_{2}$ production and stable light interaction with the composites significantly. The intensities of the transient photocurrents of $\mathrm{NiS}, \mathrm{ZnIn}_{2} \mathrm{~S}_{4}$, and NiS/ZIS by applying intermittent irradiance with continuous on-off cycles are illustrated in Fig. 10e (middle graph), where the superior output of NiS/ZIS is clear. The smaller arc radius of NiS/ZIS offers lower charge transfer hindrance, leading to faster electron transport ( $3^{\text {rd }}$ graph), which provides enhanced photocatalytic $\mathrm{H}_{2}$ reduction. For a greater understanding of these redox-based energy scavenging with photon energy, the functional materials with device performances are summarized in Table 3 .

\subsection{Selection of electrodes, redox couples, and various electrolytes}

It can be realized that almost all the energy scavenging devices based on redox reactions are closely related to the interaction between the electrodes and the redox couples or electrolytes. Actually, the device performances solely rely on the interactions among these species and the properties of the materials that are being used. In recent years, nanomaterials have become prevalent in the fabrication of energy scavenging devices because they facilitate favorable properties for faster electron transportation, better electrical and thermal conductivity, excellent light absorption with transparency, and the scope of modification through doping, surface engineering, etc. ${ }^{\mathbf{1 0 1 - 1 0 3}}$ The most important species of a redox reaction is the electrode, which plays a significant role in any type of energy scavenging technology. Previously, platinum (Pt) was the most used metal as an electrode due to its excellent electrical properties; however, it is very expensive. ${ }^{52}$ Thus, currently, carbon-related materials, for instance, nanotubes, graphite, composites, and carbon fibers have been studied intensely for electrodes due to their low cost and excellent conductive properties. ${ }^{36,48,53,56,81}$ Multiwalled carbon nanotube-coated (MWCNTs) electrodes show excellent device output compared to other electrodes, as illustrated in Fig. 11a, for electrochemistry-based energy scavenging. ${ }^{25}$ Besides, the Seebeck coefficient, redox-couple entropy, and maximum output power depend on the electrode, as presented in Fig. $11 \mathrm{~b}$, where the $1^{\text {st }}$ bar graph shows the different effects with the same redox couple $\left(\left[\mathrm{Fe}(\mathrm{CN})_{6}\right]^{4-} /\left[\mathrm{Fe}(\mathrm{CN})_{6}\right]^{3-}\right)$ with $0.4 \mathrm{M}$ $\mathrm{X}_{2} \mathrm{SO}_{4}$ (blue bars) and $1 \mathrm{M} \mathrm{XCl}$ (purple bars) with different electrodes. This graph suggests that Cs should be used as an electrode with the sated redox couple and electrolytes. ${ }^{94}$ Porosity plays an important role as it allows high surface area for chemical reactions and also increases the photoabsorption and electron diffusion for dye-sensitized solar cells. ${ }^{57}$

The maximum voltage that can be generated in an electrochemical system is closely related to the Seebeck coefficients of the redox couples. Thus, the redox couples not only participate in redox reactions with the electrodes but also control the optimum generated device outputs. The number of redox couples is restricted by their chemical stability, reversibility, and availability. The importance of choosing an appropriate redox couple with the device fabrication can be realized from Fig. 11c, showing the effectiveness of different catalysts on the generated electrical potentials using different redox couples in photocatalytic energy scavenging devices. ${ }^{70}$ Aqueous electrolytes are used during device fabrication because of their extended electron diffusion rate to obtain higher performances. Nonaqueous electrolytes are required to operate at a higher temperature, and they can solvate insoluble redox couples or stabilize the redox couples under harsh conditions. ${ }^{119,120}$ The surface area, porosity, resistivity, and permeability impact the flow-through electrode as highly effective electrodes in electrochemistry, which is determined by the mass-transport-limited current, $I_{\mathrm{L}} \cdot{ }^{121}$

$$
I_{\mathrm{L}}=n F A_{\mathrm{r}} u C_{0}\left[1-\exp \left(-\frac{L K_{\mathrm{m}} A_{\mathrm{s}}}{u}\right)\right]
$$



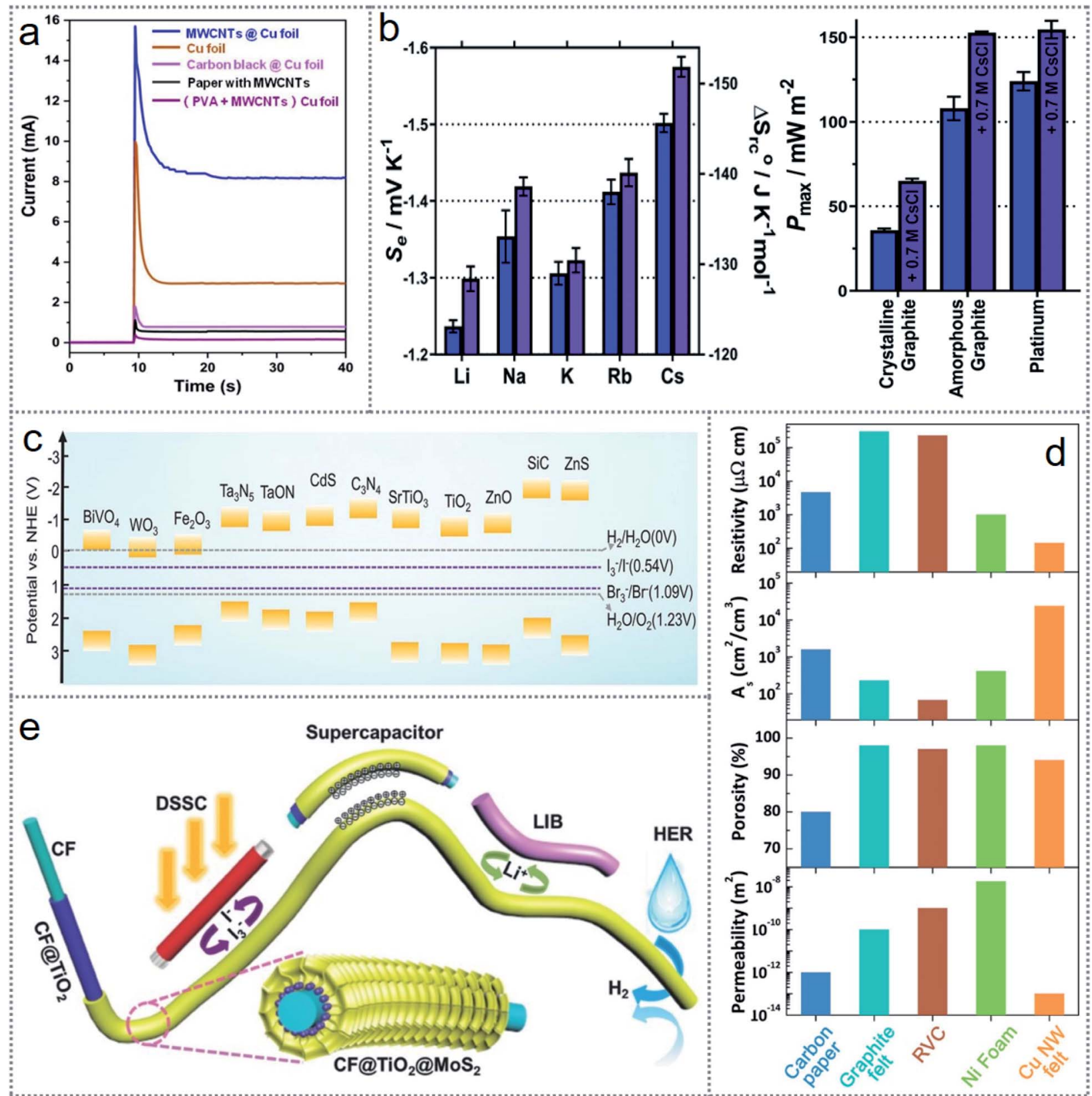

Fig. 11 Performances of several electrodes, redox couples, and various electrolytes. (a) Superior performance of multi-walled carbon nanotubes (MWCNTs) in energy scavenging devices. (b) Comparison among different electrodes and redox couples according to their Seebeck coefficients and output power density. (c) Performance of different catalysts on their outputs with different redox couples in photocatalytic energy scavenging. (d) Excellent property of $\mathrm{Cu}$ nanowire felt in photoelectrochemical energy scavenging. (e) Improvement of MoS 2 conductivity using some chemical process. Figures reproduced with permission from: (a) ref. 25, ( 2020, the American Chemical Society; (b) ref. 94, () 2020, the Royal Society of Chemistry; (c) ref. 70, (c) 2018, Wiley; (d) ref. 121, (c) 2019, the American Chemical Society; and (e) ref. 91, (c) 2017, Wiley.

where $n$ is the required electron number for the reaction, $F$ is the Faraday constant, $A_{\mathrm{r}}$ is the cross-sectional area of the electrode, $u$ denotes the superficial velocity, $C_{0}$ is reactant concentration, $L$ represents the electrode thickness and $A_{\mathrm{s}}$ is the specific surface area of the electrode. Some of the related specifications of some common electrodes are illustrated in Fig. 11d, indicating the excellent effectiveness of $\mathrm{Cu}$ nanowire felt. The modification of the electrodes with some electron mediators is intensely applied to accelerate electron transport for higher outputs. Typical $\mathrm{MoS}_{2}$ nanofilms were synthesized on $\mathrm{TiO}_{2}$ nanoparticle-coated carbon fibers, as illustrated in Fig. 11e, to utilize the high chemical activity and excellent electrical conductivity of $\mathrm{MoS}_{2} .{ }^{81}$ For a better understanding, the selection of materials for fabricating redox-based energy scavenging devices and performance enhancement through different techniques with the fabrication materials are summarised in Tables 1-3. 


\section{Applications in self-powered sensor systems of redox-based energy scavenging devices}

As already mentioned, the generated power from redox-based devices is relatively low compared to the traditional power generation and even less than that of some excellent solar cells, but the scope of applications of these devices in some sensors and low-powered devices has led to intense investigations. The output generated by these energy scavenging devices is promisingly adequate for powering many wearable, wireless, and biomedical sensors without any external energy sources. Recently, research on wearable electronic gadgets equipped with sensors having a mini display showing the real-time monitored data such as a watch and wireless transmission of the data without any external powering techniques is making the scientists very optimistic about their bright future of them. Furthermore, these energy scavenging devices generate clean energy without any toxic emissions by replacing batteries, which contain toxic materials.

\subsection{Applications of electrochemistry-based redox devices}

To date, several self-powered sensor devices that function through redox reactions have been introduced. Considering their flexibility, reliability, and admirable performances, they can be used in health monitoring and biomedical analysis applications. Many of the fabricated devices are capable of multifunction. A multifunctional redox-based energy generating device was introduced, which was used to power a wireless heartbeat sensing device (Fig. 12a) that could transmit the data to a cellphone without any external energy supply. ${ }^{25}$ The same device could sense the level of lactic acid in human sweat while generating electricity through the redox reactions simultaneously. Thus, multifunctionality can be another advantage of these devices. A real-time glucose monitoring sensor integrated with a self-powered smartwatch (Fig. 12b) was designed, which could sense the level of glucose and show the result on a E-ink display with the required data processing as a compact device. ${ }^{122}$ The generated power through redox reaction was analyzed and the result was displayed on the display by the integrated photovoltaic solar cell, which led to a hybridized sensor device. A stretchable self-powered strain sensor based on nanocomposites was introduced, having a stretchability of up to $150 \%$ and could detect human motion effectively. ${ }^{53}$

A novel microbial fuel cell (MFC)-based electrochemical sensing device for the detection and monitoring of $\mathrm{H}_{2} \mathrm{O}_{2}$ (hydrogen peroxide) was reported, which possessed a graphite cathode for the sensing mechanism and bioanode for energy supply. ${ }^{123}$ A schematic of the chemical sensor is shown in Fig. 12c (leftmost figure), showing that the generated free electrons from the bioanode will initiate the reduction at the graphite cathode to detect $\mathrm{H}_{2} \mathrm{O}_{2}$ in the range of 1 to $2000 \mathrm{mM}$. The response current of the chemical sensor with a variation in $\mathrm{H}_{2} \mathrm{O}_{2}$ concentration is shown in Fig. 12c (middle graph), where every saturated current level represents a different concentration of $\mathrm{H}_{2} \mathrm{O}_{2}$, which could be obtained within a fast response time of $5 \mathrm{~s}$. The stable operation of the device showed excellent results, where the fabricated device could deliver almost $95.7 \%$ of its initial response value after 5 months with a cation exchange membrane, as shown in Fig. 12c (rightmost graph). For further simplification, an MMFC (membraneless microfluidic fuel cell) $\mathrm{H}_{2} \mathrm{O}_{2}$ sensor was investigated, which used a single stream of $\mathrm{H}_{2} \mathrm{O}_{2}$ as the oxidant and fuel simultaneously. ${ }^{124} \mathrm{~A}$ schematic of the MMFC sensor is presented in Fig. 12d (left side-upper image) and the right side upper graph shows the increase in the response voltage with an increase in $\mathrm{H}_{2} \mathrm{O}_{2}$ concentration. The steady-state response current of the sensor with the corresponding $\mathrm{H}_{2} \mathrm{O}_{2}$ concentration is shown in Fig. 12d (left side bottom graph) and the result comparison between the sensor output with the regression calculated values with random concentrations of $\mathrm{H}_{2} \mathrm{O}_{2}$ is depicted in Fig. 12d (right side bottom graph). Besides, the excellent response time $(<1 \mathrm{~m})$ of the sensor suggests its promising applicability in portable devices or online detection remotely. A self-powered microbial fuel cell-based environment monitoring biosensor was fabricated, which generated electricity from plants (Oryza sativa) and could supply power to an IoT (internet of things) framework to process the monitored data surrounding the environment. ${ }^{125}$ Many types of fuel cells have been developed in the last 50 years due to their capability of generating required power by the sensing mechanism through redox reactions. ${ }^{126}$ Thereby, the flexible device structure of redox-based selfpowered sensors with reliable performance causes them to be attractive to the research community in versatile research fields.

A battery-free wearable microfluidic integrated skin mountable electrochemical self-powered sensor was fabricated, which could monitor the $\mathrm{K}^{+}$(potassium ion) level by harvesting human sweat and transmit the real-time data through NFC (near field communication) wirelessly. ${ }^{127} \mathrm{~A}$ schematic of the sensor structure is shown in Fig. 12e (left side image), presenting multiwalled carbon nanotubes (MWCNTs) and MXene- $\mathrm{Ti}_{3} \mathrm{C}_{2} \mathrm{~T}_{x}$-based three-dimensional internal structure with the used components. The selectivity of the $\mathrm{K}^{+}$sensor in terms of potential difference is presented in Fig. 12e (right side upper graph), where the stable voltage for every level ensured the excellent selectivity of the sensor for $\mathrm{K}^{+}$over the other ions in human sweat. Also, the repeatability and reusability of the fabricated sensor provided reliable and optimistic results, as shown in Fig. 12e (right side bottom graph). A similar, self-powered, skinattachable, and stretchable glucose and $\mathrm{pH}$ sensor, ${ }^{128}$ and textile-based wearable $\mathrm{pH}$ sensor ${ }^{129}$ were fabricated, which work based on sweat scavenging through redox reactions. Thus, these wearables, stretchable, flexible, and reliable devices have a promising future for the real-time supervision of physiological fluids in healthcare and personal life significantly.

\subsection{Applications of thermogalvanic effect-based redox devices}

Most of the applications of thermogalvanic effect-based energy scavenging devices are related to utilizing waste heat from the surrounding and converting it into electrical energy. However, 


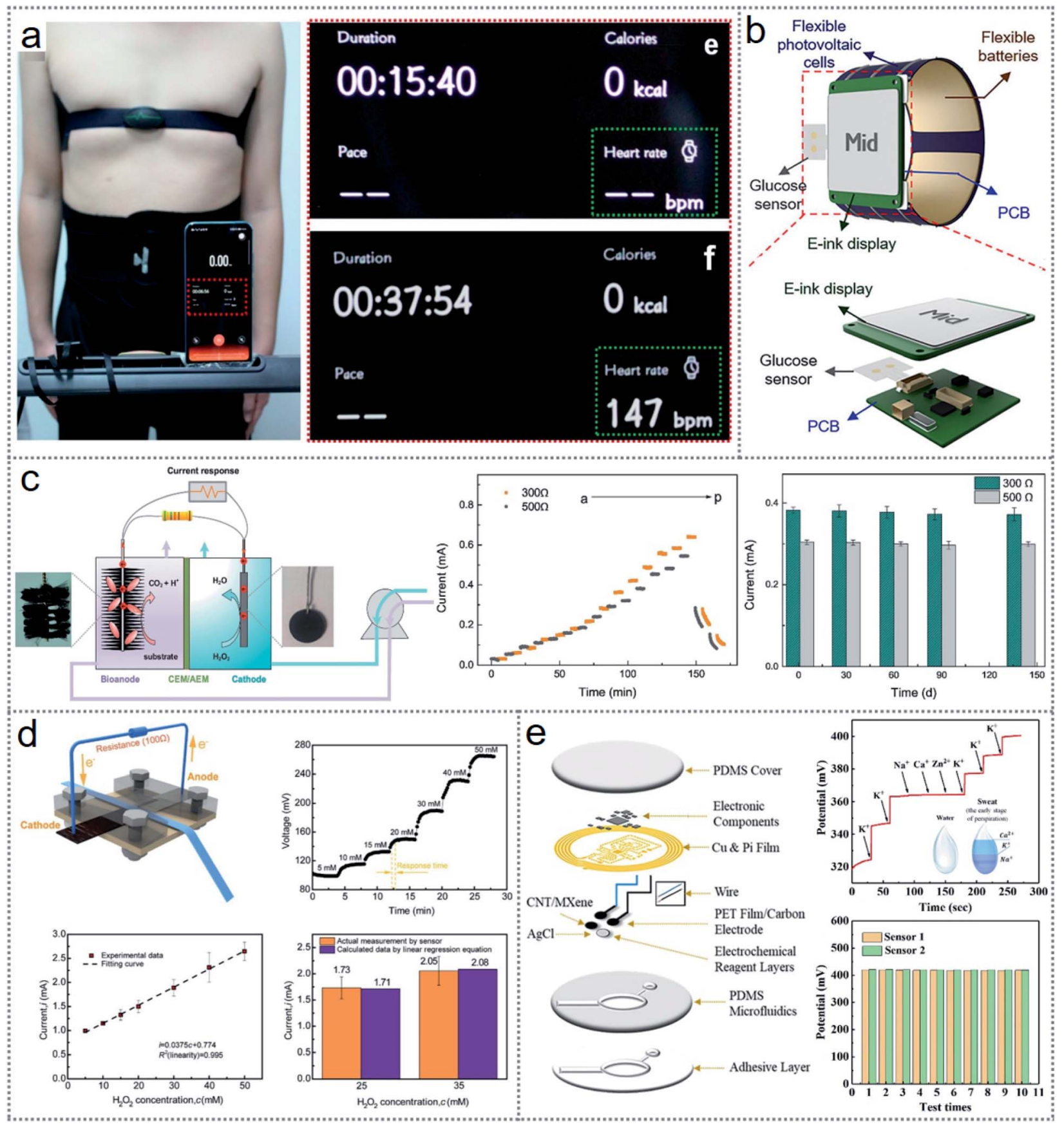

Fig. 12 Applications of electrochemical effect-based redox devices. (a) Optical image of the wireless heartbeat sensing device. (b) Schematic of the architecture of glucose monitoring sensor integrated with a self-powered smartwatch. (c) Schematic of the microbial fuel cell (MFC)-based electrochemical sensor and performances of the device. (d) Schematic of the membraneless microfluidic cell (MMFC) sensor and detection performances of the device. (e) Schematic of the battery-free integrated skin mountable electrochemical sensors and the sensing performance of the device. Figures reproduced with permission from: (a) ref. 25, () 2020, the American Chemical Society; (b) ref. 122, ( ) 2019, the American Chemical Society; (c) ref. 123, (c) 2019, Elsevier; (d) ref. 124, () 2020, the American Chemical Society; and (e) ref. 127, (c) 2021, Elsevier.

these devices have some alternative uses, which have not been investigated intensely. Several works found in the literature are different from the conventional concepts to utilize waste heat in an alternative way. Due to the use of liquid-state electrolytes and other aqueous media for redox reactions, the size and fabrication challenges make these devices adverse to large integration for wearable sensor applications. ${ }^{130}$ Thus, for designing wearable and flexible thermogalvanic cells, the gel-type electrolyte is an excellent alternative. Several gel electrolyte-based body-heat scavenging thermogalvanic cells have been integrated, as shown in Fig. 13a, to develop self-powered systems for wearable electronic devices. ${ }^{85}$ The outputs of the integrated device are illustrated in Fig. 13b (upper two graphs). The first graph demonstrates the corresponding voltage and current 
generated by the change in temperature. The inset denotes the integrated PVA/ferric/ferrous chloride (PFC) and PVA/potassium ferricyanide/ferrocyanide (PPF) thermogalvanic devices. The second graph represents the dependency of the generated power and voltage on the output current at $10{ }^{\circ} \mathrm{C}$. From an application perspective, the fabricated device was used for charging a $100 \mu \mathrm{F}$ capacitor at $0.55 \mathrm{~V}$ within $120 \mathrm{~s}$, as shown in Fig. 13b (right side of the bottom graph) by simply by wearing

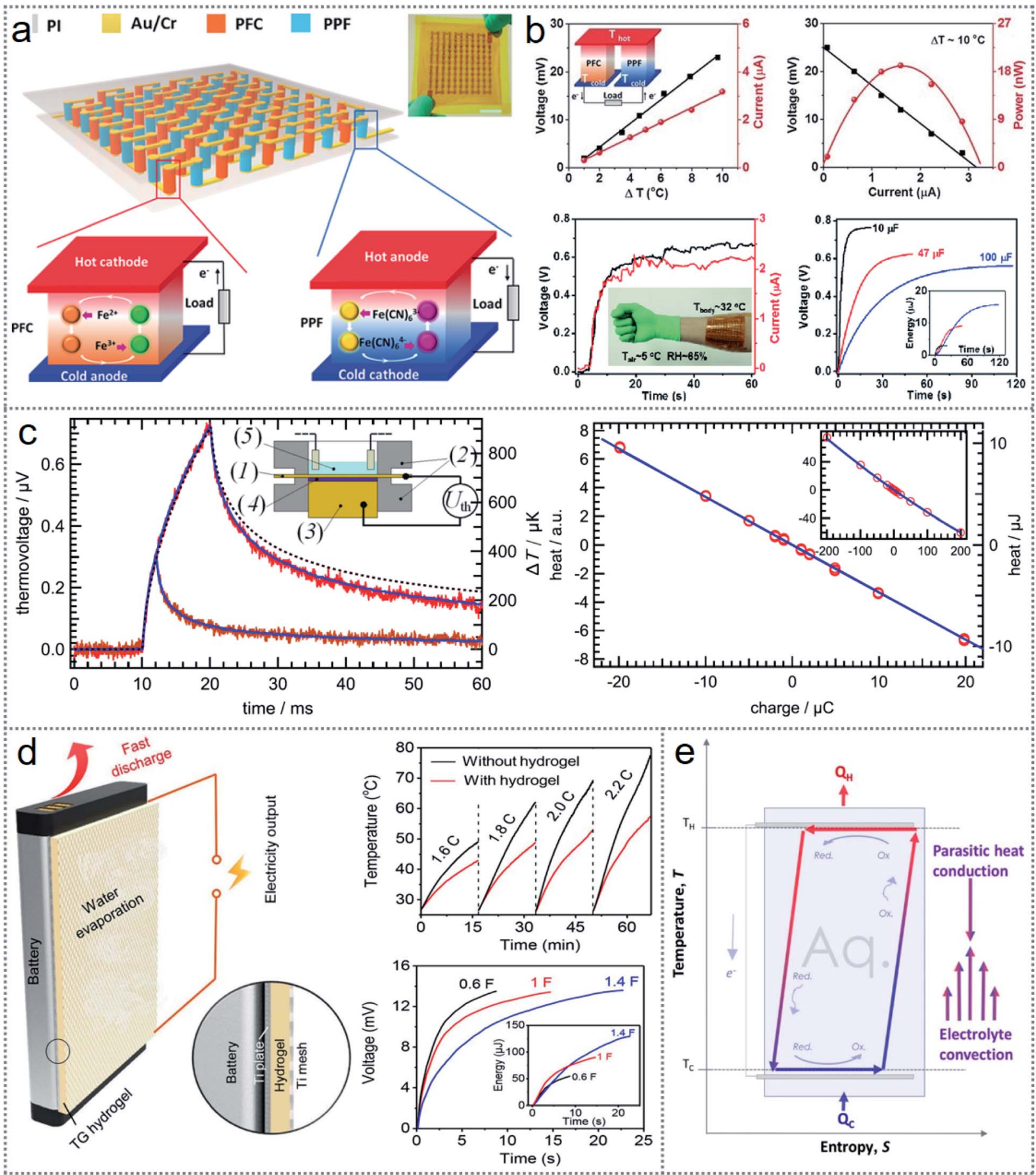

Fig. 13 Applications of thermogalvanic effect-based redox devices. (a) Integration of electrolyte-based body-heat scavenging thermogalvanic cells. (b) Output performances of the integrated device with application performance in capacitor charging. (c) Thermogalvanic response of heated gold surface (left side graph) and generated current pulses (right side graph) from the sensor cell. (d) Schematic of attached hydrogel with a cell battery (left side image), cooling capability (right side upper figure), storing capacity (right side bottom graph) of the converted energy by the cell. Figures reproduced with permission from: (a) and (b) ref. 85, (c) 2016, Wiley; (c) ref. 131, (c) 2020, the American Institute of Physics; (d) ref. 89, (c) 2020, the American Chemical Society; and (e) ref. 134, (c) 2019, Nature. 
the device on the arm, as shown in Fig. 13b (left side image of the bottom side).

A surface temperature measuring thermogalvanic cell was introduced, which has an excellent response time $(<300 \mu \mathrm{s})$ in the microsecond range. ${ }^{131}$ The thermogalvanic response of the heated $\mathrm{Au}$ (gold) surface is illustrated in Fig. 13c (left side graph), where the laser pulses of $2 \mathrm{~ms}$ and $10 \mathrm{~ms}$ are red and blue and the dashed black lines denote single pulse averaging of $40 \mathrm{~ms}$ and $10 \mathrm{~ms}$ simulated pulse, respectively. The device configuration with the gold foil (1), cell block (2), gold cylinder (3), the electrode with the electrolyte (4), and upper space containing two platinum (Pt) electrodes (counter and reference) is displayed in the inset. The Au film acts as the working electrode, and thus the electron transfer will be very fast through a redox reaction. The generated current pulses with a change in amplitude and signs of the measured heat of $10 \mathrm{~ms}$ laser pulse charge are shown in Fig. 13c (right side graph) with the large pulse-charge interval response in the inset. The proportional response indicates a linear conversion, which will provide good sensitivity. Based on the thermogalvanic effect, a thermally chargeable capacitor has been introduced ${ }^{132}$ and waste heat scavenging from internal combustion engine ${ }^{133}$ has been investigated, justifying the practical applicability of redox reaction-based devices.

Some novel applications of the thermogalvanic effect have been reported in the literature. A thermogalvanic (TG) hydrogel was synthesized, which could be used with the conventional batteries, facilitating cooling of the fast discharging heat with additional energy scavenging from that waste heat. ${ }^{89} \mathrm{~A}$ schematic of the attached hydrogel with its electrode material with the battery is shown in Fig. 13d (left side image). The cooling capability of the TG hydrogel is presented in Fig. 13d (right side upper graph), showing a comparison of the working temperature with the TG hydrogel and without it. Also, the waste heat could be turned into electrical energy and stored by capacitors, as presented by Fig. 13d (right side bottom graph). Another amazing novel concept of the redox reaction-based thermogalvanic process is electrochemical redox refrigeration. ${ }^{134,135}$ Fig. 13e shows the concept of redox cooling by using liquid, where the joule heat can be transported from the cold junction by advection heat flow without any loss in entropy, which leads to refrigeration. ${ }^{134}$ The further development of this technology will help to reduce the use of toxic hydrochlorofluorocarbons (HCHFs) and other toxic gases. More research on related redox chemistry, electrode modification, redox couples, and electrolyte choices can open many doors to the significant applications of these thermogalvanic energy scavenging devices.

\subsection{Applications of photoelectrochemistry-based redox devices}

The photon energy from light can be harvested through redox reactions with photo-sensitive electrodes, which can be utilized for fabricating many small electronics and wearable sensors. Reasonably, the most copious sustainable energy source is solar energy. Thereby, many photoelectrochemical redox reactions are initiated by solar irradiance. Many sensors based on redox- based photoelectrochemical energy scavenging devices have been fabricated such as glucose sensors, ${ }^{136,137}$ aptasensors, ${ }^{138-141}$ immunusensors, ${ }^{142}$ and photodetectors. ${ }^{143}$ A hematite $\left(\mathrm{Fe}_{2} \mathrm{O}_{3}\right)$ nanorod-based self-powered photoelectrochemical glucose sensor was fabricated, showing excellent sensitivity and selectivity with extended stable operation. ${ }^{136} \mathrm{~A}$ schematic illustration and mechanism of the device are presented in Fig. 14a (leftmost image), where $\mathrm{Fe}_{2} \mathrm{O}_{3} /$ FTO is used as the photoanode and Pt wire as the cathode. For generating electricity, it uses solar irradiance for oxidizing glucose on the photoanode surface, and the generated free electrons travel through the exterior circuit towards the cathode, where oxygen reacts with them. The generated output power density depends on the concentration of the glucose, as shown in Fig. 14a (middle graph), where 0.993 is the correlation coefficient and $94.31 \mu \mathrm{A} \mathrm{cm}{ }^{-2} \mathrm{mM}^{-1}$ is the sensitivity. The selectivity of the device is also very impressive, as presented in Fig. 14a (rightmost graph), where it can be observed that glucose shows an excellent response in the presence of other interferents. Similarly, utilizing the oxidation of glucose, another heterostructure glucose sensor was reported with excellent performances. ${ }^{137}$

Nowadays, self-powered photoelectrochemical aptamer biosensors for sensing many biological molecules or organisms are being synthesized because they have excellent sensitivity and selectivity, low background noise, low cost, and flexible operation. ${ }^{144} \mathrm{~A}$ cathodic photoelectrochemical and self-powered biosensor based on a $\mathrm{CuO}-\mathrm{Cu}_{2} \mathrm{O}$ nanowire array on copper $(\mathrm{Cu})$ mesh $\left(\mathrm{CuO}-\mathrm{Cu}_{2} \mathrm{O} \mathrm{NWA} / \mathrm{CM}\right)$ electrodes was fabricated for sensing PSA (prostate-specific antigen) with good sensor performances. ${ }^{138}$ The construction and the working mechanism of the aptasensor are illustrated in Fig. 14b. Given that both bands (conduction and valence) of $\mathrm{Cu}_{2} \mathrm{O}$ are below that of $\mathrm{CuO}$, under light irradiance, the photogenerated electrons flow from $\mathrm{Cu}_{2} \mathrm{O}$ to $\mathrm{CuO}$ and are scavenged by the electron acceptors (oxygen) in the electrolyte. Then, the $\mathrm{Cu}$ mesh attracts the flowing holes to $\mathrm{Cu}_{2} \mathrm{O}$ from $\mathrm{CuO}$ for generating a photocurrent. Due to the steric hindrance, in the absence of PSA, the contact area surface between the photoelectrode and dissolved oxygen $\left(\mathrm{O}_{2}\right)$ in the electrolyte is hampered, and consequently, the electrode active surface area is reduced, providing a degraded photocurrent response. ${ }^{138}$ However, the aptamer-modified electrode in the presence of PSA can easily attract the PSA molecules from the analyte and build the PSA-aptamer complex to release them from the detection interface. ${ }^{145}$ Thereby, the reduced steric hindrance significantly increases the photocurrent intensity and by quantitative analysis, the PSA level can be detected. Based on the aptamer modification of electrodes, many biosensors have been fabricated, which work based on the photoelectrochemical redox reaction. A self-powered PECbased detection system for the harmful hepatotoxin (released by some bacteria) was fabricated using the $\mathrm{CoO} / \mathrm{Ag} / \mathrm{g}-\mathrm{C}_{3} \mathrm{~N}_{4} \mathrm{Z}$ scheme heterojunction, which could detect the toxic level in the range of $0.1 \mathrm{pM}$ to $10 \mathrm{nM}$ with a sensing limit of $0.01 \mathrm{pM} .{ }^{139}$ Similarly, porous $\mathrm{g}-\mathrm{C}_{3} \mathrm{~N}_{4}$ nanosheets doped with phosphorus and CdS-decorated Eu-MOF (europium metal-organic framework) nanocomposite-based PEC aptasensors have been reported with excellent device performances. ${ }^{140,141}$ 

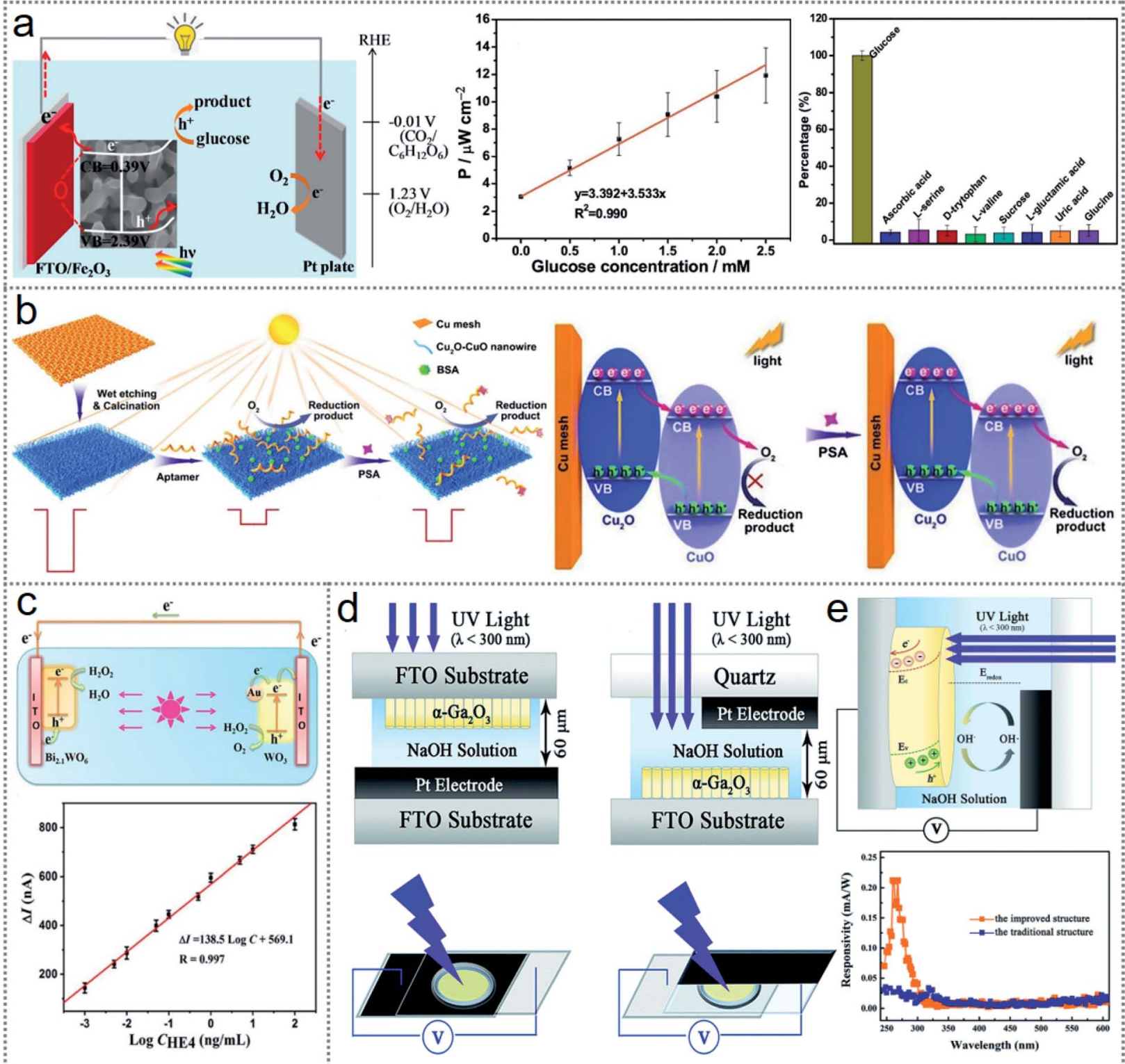

Fig. 14 Applications of photoelectrochemistry-based redox devices. (a) Schematic illustration of the working mechanism (leftmost image), measured output power density with related glucose concentration (middle graph), and selectivity (rightmost graph) of the sensor. (b) Device construction and operating principle of the aptasensor. (c) Schematic of the device with the working principle (upper image) and current response (bottom graph) of the sensor device. (d) Upgraded device fabrication compared to the traditional device. (e) Working mechanism (upper image) and response current output from the photodetector. Figures reproduced with permission from: (a) ref. 136, (c) 2020, Elsevier; (b) ref. 138, ( 2020, Springer Nature; (c) ref. 142, @ 2020, the American Chemical Society; and (d) and (e) ref. 143, ( 2020, the American Physical Society.

A PEC immunosensor to detect human epididymal protein 4 (HE4) was fabricated using a novel photocathode Bi-doped $\mathrm{W}_{2} \mathrm{O}_{6} \mathrm{p}-\mathrm{n}$ homojunction and $\mathrm{WO}_{3} / \mathrm{Au}$ as the photoanode to sense and amplify the signal, respectively. ${ }^{142} \mathrm{~A}$ schematic of the structure of the immunosensor with its operation principle is presented in Fig. 14c (upper image). When visible light is applied in the absence of HE4, the electrodes are excited to produce electron-hole pairs. The holes in the $\mathrm{VB}$ of ITO/ $\mathrm{WO}_{3} / \mathrm{Au}$ are neutralized in the presence of $\mathrm{H}_{2} \mathrm{O}_{2}$. The photogenerated electrons in the $\mathrm{CB}$ (conduction band) of ITO/ $\mathrm{WO}_{3} / \mathrm{Au}$ enter the $\mathrm{VB}$ (valence band) of $\mathrm{ITO} / \mathrm{Bi}_{2.1} \mathrm{WO}_{6}$ across the exterior load, where the electrons in the $\mathrm{CB}$ of $\mathrm{ITO} / \mathrm{Bi}_{2.1} \mathrm{WO}_{6}$ are attracted to the $\mathrm{H}_{2} \mathrm{O}_{2}$ electron acceptors to amplify the response signals. When the incubated HE4 is present on the photocathode, it will defend $\mathrm{H}_{2} \mathrm{O}_{2}$ from accepting the electrons, showing a lower photocurrent. An increase in the concentration of HE4 will decrease the response current, as shown in Fig. 14c (bottom graph). Thus, the sensor delivered excellent sensitivity with few interferences for detection, having a sensing limit of $77.8 \mathrm{fg}$ $\mathrm{mL}^{-1}$ in the concentration range of 0.001 to $100 \mathrm{ng} \mathrm{mL}^{-1}{ }^{142} \mathrm{~A}$ novel ultraviolet (UV) photodetector by a self-powered PEC sensor was introduced, where the counter electrode based on 
$\mathrm{Ga}_{2} \mathrm{O}_{3}$ was redesigned to enhance the device performance. ${ }^{143}$ The improvement in the design of the new UV detector compared to the traditional one is illustrated in Fig. 14d, where the right side is the new one, having a high transmittance quartz glass instead of FTO, the platinum electrode does not coverer all the light passing through to the bottom substrate, and the location of $\alpha-\mathrm{Ga}_{2} \mathrm{O}_{3}$ in the $\mathrm{NaOH}$ electrolyte was changed. The operation of the newly designed detector is shown in Fig. 14e (upper image). When UV light $(\lambda<300 \mathrm{~nm})$ passes through the quartz glass, electrons hole pairs will be generated due to the absorbance of photon energy (higher than the bandgap of $\alpha-\mathrm{Ga}_{2} \mathrm{O}_{3}$ ) and the generated electron-hole pairs will be isolated because of the existing driving electric field at the interface of $\alpha-\mathrm{Ga}_{2} \mathrm{O}_{3}$ and the electrolyte. The separated electrons flow to the external circuit through the FTO and the hole pairs join in the redox reaction to form a redox molecule $\left(\mathrm{h}^{+}+\mathrm{OH}^{-} \rightarrow\right.$ $\left.\mathrm{OH}^{*}\right)$, which is reduced $\left(\mathrm{OH}^{\cdot}+\mathrm{e}^{-} \rightarrow \mathrm{OH}^{-}\right)$at the Pt electrode with the re-entered electrons from the circuit to complete the cycle. The extended responsivity of the newly designed UV detector is illustrated in Fig. 14e (bottom graph), showing the clear response photocurrent, which is much higher than that of the conventional UV detector. Redox-based devices are gaining more attention due to their flexibility and reliability with excellent performances in sensing and detection. However, more studies on the synthesis of novel materials and device structures can extend the device performance more cheaply.

\section{Challenges in redox-based devices}

The main challenge with redox-based energy scavenging devices is the limited efficiency of energy conversion, which makes them unsuitable from a practical perspective such as low-grade heat harvesting through thermogalvanic cells. ${ }^{\mathbf{1 4 6}}$ Over the last few decades, the applications of redox-based energy generators cover a limited area such as small household generators, portable electronic devices, wearable sensor devices, small boats, and most importantly for some remote sensor networks for monitoring some environmental parameters such as temperature, pollutant detection in water and the detection of some gases. ${ }^{46}$ Another major challenge for all types of redox devices is their bulky and heavy structure. In most cases, especially for thermogalvanic and thermocells, the electrode materials and required redox couple with electrolyte make the device heavier compared to other energy scavenging devices.

For electrochemical redox-based devices, electrode selection is a big challenge for optimum output. Besides, a good electron shuttler need to be added as an extra compound, which transfers electrons, increasing the cost and design complexity, and especially for solid-state devices, their fabrication and sensor design can interfere with the electron shuttler. ${ }^{150}$ Sometimes, residual compounds remain, which can harm the stable operation of the device in the long run. ${ }^{\mathbf{1 4 7}}$ For microbial fuel cells, the toxins released by the bacteria can harm the cell walls, and consequently reduce the device performance. ${ }^{\mathbf{4 1}}$ However, porous electrodes are favorable for higher outputs due to their large active surface area, where the diffusion effect can affect the output currently crucially as it leads to the depletion of the ion concentration during the permeation of ions through the porous electrodes. ${ }^{\mathbf{1 4 8}}$ For thermogalvanic cells, the random temperature fluctuation can reduce the outputs given that the ambient temperature is not predictable. Solar energy scavenging through dye-sensitized solar cells (DSSC) often becomes an inferior technique due to the high cost of metallic dyes such as ruthenium-based dyes. ${ }^{\mathbf{1 4 9}}$ Photoelectrochemical water splitting devices experience sluggish kinetics during oxygen evolution at extreme $\mathrm{pH}$ values. ${ }^{\mathbf{1 5 0}}$ Also, the diffusion overpotential, the ohmic loss, and kinetic overpotentials on the electrocatalysts affect the output performance.

Finally, for the practical applications of redox-based energy scavenging self-powered sensor devices, there are still some challenges such as powering the equipped displays, data processing circuits, and data transmitting units with external batteries or another power scavenging device, which make the whole system less flexible. ${ }^{\mathbf{1 2 2}}$ Integration of all the required units in a single compact device still an extreme task. Wearable, skin-mountable, and textile-based sensor devices can create some skin irritation and uncomfortable feelings due to their interaction with body fluids. Most importantly, implantable medical devices still have some major challenges including a lack of biocompatibility, which can initiate some infections and inflammation due to the toxicity of the fabrication materials, and the longevity of devices is crucial as it is not possible to replace the implanted device frequently through a surgical operation. ${ }^{151}$ All these limitations and challenges can be defended through profound investigations to determine better ways to synthesize new materials to redesign these devices by gathering extended knowledge on redox chemistry.

\section{Conclusion and future aspects}

Large-scale scavenging of the surrounding sustainable resources is still a big challenge for the scientific community, but some amazing inventions such as triboelectric energy scavengers have become promising in addressing the energy crisis. ${ }^{\mathbf{1 5 2}}$ Also, this will be possible if all the available ways are studied deeply and the overall development of energy scavenging devices with novel materials and storing systems are investigated thoroughly. ${ }^{153}$ In this united goal, redox-based energy scavenging devices are one of the robust ways to scavenge energy through electrochemical, thermochemical, and photoelectrochemical processes. Energy scavenging techniques used in electrochemical, thermo-electrochemical, and photoelectrochemical processes through redox-based devices are economical, flexible, reliable, and renewable methods without destroying the ecological balance of the Earth given that there are no emissions or harmful radiation. In recent years, a momentous improvement in energy conversion efficiency and sensing mechanism of these devices has been achieved. The substantial achievements in energy harvesting self-powered sensor devices have already laid the foundation in several directions for the commercialization and applicability of these devices by defending the key challenges. However, more intense investigations are required to overcome the major obstacles. In this perception, the underlying knowledge of redox chemistry, 
interconnections among the electrodes, redox couples, electrolytes, and driving forces, and the effective device design with related parameters and materials properties are the most essential concerns.

The fundamental properties that must be studied more deeply for a better understanding to extend the outputs are the optimization of the Seebeck coefficients of the redox couples, increasing the change in entropy, and extension of the absorbance of photons. The correlated factors that affect the whole process from the material synthesis to the device operation in different surrounding conditions should be analyzed for an overall improvement. Although the selection of the material may vary according to the driving energy or application, the synthesis of novel materials is necessary for special cases. As an example, if a self-powered device is designed for an implantable sensor for the human body, then the biocompatibility and nontoxicity of a material that is capable to generate the minimum required power is preferable than toxic/bio-incompatible materials having the capability of excessive power generation because of the potential health hazards. To make redox-based devices more effective, faster electron transport is an urgent need. Thereby, the choice of an electron shuttle requires fundamental analysis of the electrolytes working in different physical states. The aqueous medium is reported in the majority of investigations for faster electron transportation, which is troublesome in many applications, and thus more research is required for the selection of electrolytes to make them viable in every condition as required. Redox couples interact with the electrodes directly and initiate energy scavenging by the driving force of external sustainable energy sources that are to be harvested. Given that the number of redox couples is still very limited, novel redox couples with higher Seebeck coefficients need to be the focus. Besides, the operating temperature is an important factor in conductivity from an electrical and thermal perspective, and the resistivity of the electrode used in the device fabrication may affect the device outputs. Thus, a better understanding of the temperature effect should be reported carefully for the fundamental understanding of the chemistry of redox-based energy scavenging devices.

Besides fundamental knowledge on redox chemistry, some other factors such as effective design, applying surface engineering or modification to electrodes, phase-changing effects, computational models, and simulation analysis can play a significant role in redox-based devices in energy scavenging and self-powered sensor systems. Currently, carbon-originated compounds such as carbon nanotubes, carbon fibers coated with nanostructures, and graphite electrodes are being used vastly with the introduction of porosity, which enhances the photocatalytic, electrocatalytic properties. A large surface area with excellent chemical activity and soft nature and stretchability are significant properties required for wearable and implantable sensor applications, which have been obtained with the help of nanotechnology and technological advancement. More intensive experimental studies need to be conducted in the search for more suitable electrodes and related materials for device fabrication. Thus, new and suitable materials depending on the requirement can be found easily, assuming their low-cost, high current density, and diversity. Most of the reported works in redox-based energy scavenging and self-powered sensors devices for various applications are experimental-oriented without any computational analysis, which is not suitable for uncertain device performances. Developing a computable analysis through some cross-relations among the electrodes, redox couples, electrolytes, driving energy and device structure can significantly predict the device performances before device fabrication. The computational analysis can be developed into some simulation-based device fabrication by simulating some simple parameters related to the device components, which will lead to choosing the best electrodes with suitable redox couples and electrolytes. Also, through these simulative ways, device optimization will be easier to fabricate some excellent devices within a short period. However, this requires more contributions from researchers from all scientific areas. In conclusion, redox-based devices need a combined effort from chemists, chemical engineers, materials scientists, renewable energy scholars, physicists, and scholars from related backgrounds for the development of some advanced energy scavenging technologies, which will ensure a clean energy supply with self-powered implantable and wearable sensor systems without any fear of potential risk to humans.

\section{Author contributions}

Ya Yang conceived the idea and supervised the whole process. Md Al Mahadi Hasan has surveyed the literature, prepared the outline and wrote the manuscript. Ya Yang and Heting $\mathrm{Wu}$ revised the outline. All the authors revised the manuscript.

\section{Conflicts of interest}

There are no conflicts to declare.

\section{Acknowledgements}

This work was supported by the National Key R \& D Project from the Minister of Science and Technology in China (No. 2016YFA0202701), the National Natural Science Foundation of China (No. 52072041), Qingdao National Laboratory for Marine Science and Technology (No. 2017ASKJ01), the Chinese Government Scholarship by Chinese Scholarship Council, and the University of Chinese Academy of Sciences (No. Y8540XX2D2).

\section{References}

1 P. M. Kumar, V. Jagadeesh Babu, A. Subramanian, A. Bandla, N. Thakor, S. Ramakrishna and H. Wei, Designs, 2019, 3, 22.

2 I. Kralova and J. Sjöblom, J. Dispersion Sci. Technol., 2010, 31, 409-425.

3 Y. Yang, H. Zhang, Z. H. Lin, Y. S. Zhou, Q. Jing, Y. Su, J. Yang, J. Chen, C. Hu and Z. L. Wang, ACS Nano, 2013, 7, 9213-9222. 
4 X. Chen, X. Ma, W. Ren, L. Gao, S. Lu, D. Tong, F. Wang, Y. Chen, Y. Huang, H. He and B. Tang, Cell Rep. Phys. Sci., 2020, 1, 100207.

5 Y. Song, N. Wang, Y. Wang, R. Zhang, H. Olin and Y. Yang, Adv. Energy Mater., 2020, 10, 2002756.

6 J. M. Wu, C. Y. Chen, Y. Zhang, K. H. Chen, Y. Yang, Y. Hu, J. H. He and Z. L. Wang, ACS Nano, 2012, 6, 4369-4374.

7 K. Song, R. Zhao, Z. L. Wang and Y. Yang, Adv. Mater., 2019, 31, 1902831.

8 Y. Yang, Y. Zhou, J. M. Wu and Z. L. Wang, ACS Nano, 2012, 6, 8456-8461.

9 Y. Ji, Y. Wang and Y. Yang, Adv. Electron. Mater., 2019, 5, 1900195.

10 Y. Yang, Z. H. Lin, T. Hou, F. Zhang and Z. L. Wang, Nano Res., 2012, 5, 888-895.

11 D. Zhang, Y. Wang and Y. Yang, Small, 2019, 15, 1805241.

12 J. Sun, W. Li, Y. Li, Y. Hu and Y. Zhang, Bioresour. Technol., 2013, 142, 407-414.

13 Y. Ji, K. Zhang, z. l. Wang and Y. Yang, Energy Environ. Sci., 2019, 12, 1231-1240.

14 K. Zhang, S. Wang and Y. Yang, Adv. Energy Mater., 2017, 7, 1601852.

15 K. Zhang, Z. L. Wang and Y. Yang, ACS Nano, 2016, 10, 10331-10338.

16 X. Wang, Z. L. Wang and Y. Yang, Nano Energy, 2016, 26, 164-171.

17 N. Ma, K. Zhang and Y. Yang, Adv. Mater., 2017, 29, 1703694.

18 K. Zhao, B. Ouyang, C. R. Bowen and Y. Yang, Nano Energy, 2020, 77, 105152.

19 B. Ouyang, C. Chang, L. D. Zhao, Z. L. Wang and Y. Yang, Nano Energy, 2019, 66, 104111.

20 W. Qian, K. Zhao, D. Zhang, C. R. Bowen, Y. Wang and Y. Yang, ACS Appl. Mater. Interfaces, 2019, 11, 27862-27869.

21 O. Ellabban, H. Abu-Rub and F. Blaabjerg, Renewable Sustainable Energy Rev., 2014, 39, 748-764.

22 M. Søndergaard, Encyclopedia of inland waters, Academic Press, Oxford, 2009, pp. 852-859.

23 R. Jono, Y. Tateyama and K. Yamashita, Phys. Chem. Chem. Phys., 2015, 17, 27103-27108.

24 M. L. Brusseau and J. Chorover, Environmental and Pollution Science, Academic Press, 2019, pp. 113-130.

25 H. Wu, L. Xu, Y. Wang, T. Zhang, H. Zhang, C. R. Bowen, Z. L. Wang and Y. Yang, ACS Energy Lett., 2020, 5, 37083717.

26 J. Lv, I. Jeerapan, F. Tehrani, L. Yin, C. A. Silva-Lopez, J. H. Jang, D. Joshuia, R. Shah, Y. Liang, L. Xie and F. Soto, Energy Environ. Sci., 2018, 11, 3431-3442.

27 X. Zhang, J. Yang, R. Borayek, H. Qu, D. K. Nandakumar, Q. Zhang, J. Ding and S. C. Tan, Nano Energy, 2020, 75, 104873.

28 S. K. Chaudhuri and D. R. Lovley, Nat. Biotechnol., 2003, 21, 1229-1232.

29 M. Sun, L. F. Zhai, W. W. Li and H. Q. Yu, Chem. Soc. Rev., 2016, 45, 2847-2870.

30 Y. Wang, Y. Jiang, H. Wu and Y. Yang, Nano Energy, 2019, 63, 103810.
31 Y. Wang and Y. Yang, Nano Energy, 2019, 56, 547-554.

32 D. Jiang, B. Shi, H. Ouyang, Y. Fan, Z. L. Wang and Z. Li, ACS Nano, 2020, 14, 6436-6448.

33 J. Kim, I. Jeerapan, J. R. Sempionatto, A. Barfidokht, R. K. Mishra, A. S. Campbell, L. J. Hubble and J. Wang, Acc. Chem. Res., 2018, 51, 2820-2828.

34 D. Wang, S. H. Lee, J. Kim and C. B. Park, ChemSusChem, 2020, 13, 2807.

35 M. Zohair, K. Moyer, J. Eaves-Rathert, C. Meng, J. Waugh and C. L. Pint, ACS Nano, 2020, 14, 2308-2315.

36 H. Li, X. Zhang, L. Zhao, D. Jiang, L. Xu, Z. Liu, Y. Wu, K. Hu, M. R. Zhang, J. Wang and Y. Fan, Nano-Micro Lett., 2020, 12, 1-12.

37 D. Jiang, B. Shi, H. Ouyang, Y. Fan, Z. L. Wang and Z. Li, ACS Nano, 2020, 14, 6436-6448.

38 S. Baltsavias, W. Van Treuren, M. J. Weber, J. Charthad, S. Baker, J. L. Sonnenburg and A. Arbabian, IEEE Trans. Biomed. Eng., 2019, 67, 1821-1830.

39 H. Wang, F. Teng, L. Zhang, Q. Zhang, H. Zhang, T. Pei, S. Li and L. Xia, ACS Appl. Mater. Interfaces, 2019, 11, 2952229535.

40 D. R. Lovley, Nat. Rev. Microbiol., 2006, 4, 497-508.

41 F. Ndayisenga, Z. Yu, G. Yan, I. A. Phulpoto, Q. Li, H. Kumar, L. Fu and D. Zhou, Sci. Total Environ., 2021, 751, 142292.

42 M. Sun, L. F. Zhai, W. W. Li and H. Q. Yu, Chem. Soc. Rev., 2016, 45, 2847-2870.

43 Y. Wang, Y. Wang and Y. Yang, Adv. Energy Mater., 2018, 8, 1800961.

44 Y. Guo, J. Wang, S. Shinde, X. Wang, Y. Li, Y. Dai, J. Ren, P. Zhang and X. Liu, RSC Adv., 2020, 10, 25874-25887.

45 I. Atlas and M. E. Suss, Electrochim. Acta, 2019, 319, 813821.

46 T. I. Quickenden and Y. Mua, J. Electrochem. Soc., 1995, 142, 3985-3994.

47 B. Burrows, J. Electrochem. Soc., 1976, 123, 154-159.

48 J. Duan, G. Feng, B. Yu, J. Li, M. Chen, P. Yang, J. Feng, K. Liu and J. Zhou, Nat. Commun., 2018, 9, 1-8.

49 M. A. Buckingham, F. Marken and L. Aldous, Sustainable Energy Fuels, 2018, 2, 2717-2726.

50 T. C. Harman, M. P. Walsh, B. E. Laforge and G. W. Turner, J. Electron. Mater., 2005, 34, L19-L22.

51 G. J. Snyder and E. S. Toberer, Nat. Mater., 2008, 7, 105-114.

52 M. F. Dupont, D. R. MacFarlane and J. M. Pringle, Chem. Commun., 2017, 53, 6288-6302.

53 B. Yu, J. Duan, J. Li, W. Xie, H. Jin, R. Liu, H. Wang, L. Huang, B. Hu and J. Zhou, Research, 2019, 2019(10), 2460953.

54 S. Kandhasamy, G. M. Haarberg, S. Kjelstrup and A. Solheim, J. Energy Chem., 2020, 41, 34-42.

55 L. Yang, H. Sun, S. Wang, L. Jiang and G. Sun, Int. J. Hydrogen Energy, 2017, 42, 25877-25881.

56 T. Ding, L. Zhu, X. Q. Wang, K. H. Chan, X. Lu, Y. Cheng and G. W. Ho, Adv. Energy Mater., 2018, 8, 1802397.

57 Q. Zhao, X. Guo, H. Zhang, M. Ni and S. Hou, Energy Convers. Manage., 2019, 195, 1227-1237. 
58 P. A. Linford, L. Xu, B. Huang, Y. Shao-Horn and C. V. Thompson, J. Power Sources, 2018, 399, 429-435.

59 Y. Ding, X. Guo, K. Ramirez-Meyers, Y. Zhou, L. Zhang, F. Zhao and G. Yu, Energy Environ. Sci., 2019, 12, 3370-3379. 60 A. J. Bard, Science, 1980, 207, 139-144.

61 N. C. D. Nath and J. J. Lee, J. Ind. Eng. Chem., 2019, 78, 5365.

62 K. Kakiage, Y. Aoyama, T. Yano, K. Oya, J.-I. Fujisawa and M. Hanaya, Chem. Commun., 2015, 51, 15894-15897.

63 M. Freitag, J. Teuscher, Y. Saygili, X. Zhang, F. Giordano, P. Liska, J. Hua, S. M. Zakeeruddin, J.-E. Moser and M. Grätzel, Nat. Photon., 2017, 11, 372-378.

64 P. Wang, S. M. Zakeeruddin, I. Exnar and M. Grätzel, Chem. Commun., 2002, 24, 2972-2973.

65 Q. Yu, C. Yu, F. Guo, J. Wang, S. Jiao, S. Gao, H. Li and L. Zhao, Energy Environ. Sci., 2012, 5, 6151-6155.

66 D. Song, W. Cho, J. H. Lee and Y. S. Kang, J. Phys. Chem. Lett., 2014, 5, 1249-1258.

67 I. P. Liu, Y. Y. Chen, Y. S. Cho, L. W. Wang, C. Y. Chien and Y. L. Lee, J. Power Sources, 2021, 482, 228962.

68 X. Chen, S. Shen, L. Guo and S. S. Mao, Chem. Rev., 2010, 110, 6503-6570.

69 T. L. Gibson and N. A. Kelly, J. Power Sources, 2010, 195, 3928-3932.

70 Y. Zhou, S. Zhang, Y. Ding, L. Zhang, C. Zhang, X. Zhang, Y. Zhao and G. Yu, Adv. Mater., 2018, 30, 1802294.

71 S. Liao, X. Zong, B. Seger, T. Pedersen, T. Yao, C. Ding, J. Shi, J. Chen and C. Li, Nat. Commun., 2016, 7, 1-8.

72 Q. Cheng, W. Fan, Y. He, P. Ma, S. Vanka, S. Fan, Z. Mi and D. Wang, Adv. Mater., 2017, 29, 1700312.

73 Q. Li, N. Li, Y. Liu, Y. Wang and H. Zhou, Adv. Energy Mater., 2016, 6, 1600632.

74 J. Azevedo, T. Seipp, J. Burfeind, C. Sousa, A. Bentien, J. P. Araújo and A. Mendes, Nano Energy, 2016, 22, 396-405.

75 F. E. Osterloh, ACS Energy Lett., 2017, 2, 445-453.

76 L. Lin, T. Hisatomi, S. Chen, T. Takata and K. Domen, Trends Chem., 2020, 2, 813-824.

77 A. Kudo, S. Yoshino, T. Tsuchiya, Y. Udagawa, Y. Takahashi, M. Yamaguchi, I. Ogasawara, H. Matsumoto and A. Iwase, Faraday Discuss., 2019, 215, 313-328.

78 C. Li, J. He, Y. Xiao, Y. Li and J. J. Delaunay, Energy Environ. Sci., 2020, 13, 3269-3306.

79 L. Cao, K. Xu and M. Fan, J. Power Sources, 2021, 482, 228956.

80 X. Li, M. H. Hu, L. Z. Zeng, J. Xiong, B. H. Tang, Z. M. Hu, L. D. Xing, Q. M. Huang and W. S. Li, Biosens. Bioelectron., 2019, 145, 8.

81 A. J. Bandodkar, J. M. You, N. H. Kim, Y. Gu, R. Kumar, A. V. Mohan, J. Kurniawan, S. Imani, T. Nakagawa, B. Parish and M. Parthasarathy, Energy Environ. Sci., 10, 1581-1589.

82 M. S. Romano, J. M. Razal, D. Antiohos, G. G. Wallace and J. Chen, J. Nanosci. Nanotechnol., 2015, 15, 1-14.

83 H. G. Hertz and S. K. Ratkje, J. Electrochem. Soc., 1989, 136, 1698.

84 M. F. Dupont, D. R. MacFarlane and J. M. Pringle, Chem. Commun., 2017, 53, 6288-6302.
85 P. Yang, K. Liu, Q. Chen, X. Mo, Y. Zhou, S. Li, G. Feng and J. Zhou, Angew. Chem., 2016, 128, 12229-12232.

86 J. Duan, B. Yu, K. Liu, J. Li, P. Yang, W. Xie, G. Xue, R. Liu, H. Wang and J. Zhou, Nano Energy, 2019, 57, 473-479.

87 M. S. Romano, J. M. Razal, D. Antiohos, G. Wallace and J. Chen, J. Nanosci. Nanotechnol., 2015, 15, 1-14.

88 H. A. Alzahrani, M. A. Buckingham, F. Marken and L. Aldous, Electrochem. Commun., 2019, 102, 41-45.

89 S. Pu, Y. Liao, K. Chen, J. Fu, S. Zhang, L. Ge, G. Conta, S. Bouzarif, T. Cheng, X. Hu and K. Liu, Nano Lett., 2020, 20, 3791-3797.

90 J. M. Li, C. W. Tsao, M. J. Fang, C. C. Chen, C. W. Liu and Y. J. Hsu, ACS Appl. Nano Mater., 2018, 1, 6843-6853.

91 J. Liang, G. Zhu, C. Wang, Y. Wang, H. Zhu, Y. Hu, H. Lv, R. Chen, L. Ma, T. Chen and Z. Jin, Adv. Energy Mater., 2017, 7, 1601208.

92 N. Li, Y. He, J. Lian, Q. Liu, X. Zhang and X. Zhang, New J. Chem., 2020, 44, 12806-12814.

93 X. Zhang, Y. Wang, F. Hou, H. Li, Y. Yang, X. Zhang, Y. Yang and Y. Wang, Appl. Surf. Sci., 2017, 391, 476-483.

94 M. A. Buckingham, S. Hammoud, H. Li, C. J. Beale, J. T. Sengel and L. Aldous, Sustainable Energy Fuels, 2020, 4, 3388-3399.

95 M. A. Butler and D. S. Ginley, J. Mater. Sci., 1980, 15, 1-19. 96 K. Kakiage, Y. Aoyama, T. Yano, K. Oya, J.-I. Fujisawa and M. Hanaya, Chem. Commun., 2015, 51, 15894-15897.

97 Z. B. Yu, Y. P. Xie, G. Liu, G. Q. Lu, X. L. Ma and H. M. Cheng, J. Mater. Chem. A, 2013, 1, 2773-2776.

98 D. Kim, K. K. Sakimoto, D. Hong and P. Yang, Angew. Chem., Int. Ed., 2015, 54, 3259-3266.

99 G. Longatte, A. Sayegh, J. Delacotte, F. Rappaport, F. A. Wollman, M. Guille-Collignon and F. Lemaître, Chem. Sci., 2018, 9, 8271-8281.

100 L. Ding, D. Li, H. Shen, X. Qiao, H. Shen and W. Shi, J. Alloys Compd., 2021, 853, 157328.

101 S. Lin, L. Xu, C. Xu, X. Chen, A. C. Wang, B. Zhang, P. Lin, Y. Yang, H. Zhao and Z. L. Wang, Adv. Mater., 2019, 31, 1808197.

102 M. A. M. Hasan, Y. Wang, C. R. Bowen and Y. Yang, NanoMicro Lett., 2021, 13, 1-41.

103 N. Ye, J. Qi, Z. Qi, X. Zhang, Y. Yang, J. Liu and Y. Zhang, J. Power Sources, 2010, 195, 5806-5809.

104 R. A. Escalona-Villalpando, E. Ortiz-Ortega, J. P. BocanegraUgalde, S. D. Minteer, J. Ledesma-García and L. G. Arriaga, J. Power Sources, 2019, 412, 496-504.

105 W. Jia, G. Valdés-Ramírez, A. J. Bandodkar, J. R. Windmiller and J. Wang, Angew. Chem., Int. Ed., 2013, 52, 7233-7236.

106 C. Wang, E. Shim, H. K. Chang, N. Lee, H. R. Kim and J. Park, Biosens. Bioelectron., 2020, 169, 112652.

107 S. Yin, W. Liu, S. Yao, X. Du, P. Song and Z. Wang, New J. Chem., 2019, 43, 6279-6287.

108 S. W. Lee, Y. Yang, H. W. Lee, H. Ghasemi, D. Kraemer, G. Chen and Y. Cui, Nat. Commun., 2014, 5, 1-6.

109 X. Wang, Y. T. Huang, C. Liu, K. Mu, K. H. Li, S. Wang, Y. Yang, L. Wang, C. H. Su and S. P. Feng, Nat. Commun., 2019, 10, 1-8. 
110 R. Hu, B. A. Cola, N. Haram, J. N. Barisci, S. Lee, S. Stoughton, G. Wallace, C. Too, M. Thomas, A. Gestos and M. E. D. Cruz, Nano Lett., 2010, 10, 838-846.

111 S. Zhang, C. Chen, Y. Zhou, Y. Qian, J. Ye, S. Xiong, Y. Zhao and X. Zhang, ACS Appl. Mater. Interfaces, 2018, 10, 2304823054.

112 G. Yue, w. Wu, X. Liu and H. Zheng, Sol. Energy, 2018, 167, 137-146.

113 J. Chellamuthu, P. Nagaraj, S. G. Chidambaram, A. Sambandam and A. Muthupandian, J. Photochem. Photobiol., B, 2016, 162, 208-212.

114 İ. C. Kaya, S. Akin, H. Akyildiz and S. Sonmezoglu, Sol. Energy, 2018, 169, 196-205.

115 J. V. Vaghasiya, K. K. Sonigara, J. Prasad, M. Qureshi, S. C. Tan and S. S. Soni, ACS Appl. Energy Mater., 2020, 3, 7073-7082.

116 J. Y. Jung, D. W. Kim, S. S. Shinde, S. H. Kim, D. H. Kim, C. Lin, T. J. Park and J. H. Lee, ACS Appl. Mater. Interfaces, 2020, 12, 16402-16410.

117 J. Sun, P. Yang, N. Li, M. Zhao, X. Zhang, Y. Zhang, Y. Yuan, X. Lu and X. Lu, Electrochim. Acta, 2020, 336, 135710.

118 S. F. Duan, Z. X. Zhang, Y. Y. Geng, X. Q. Yao, M. Kan, Y. X. Zhao, X. B. Pan, X. W. Kang, C. L. Tao and D. D. Qin, Dalton Trans., 2018, 47, 14566-14572.

119 D. Cabral, P. C. Howlett, J. M. Pringle, X. Zhang and D. MacFarlane, Electrochim. Acta, 2015, 180, 419-426.

120 D. M. Cabral, P. C. Howlett and D. R. MacFarlane, Electrochim. Acta, 2016, 220, 347-353.

121 M. J. Kim, Y. Seo, M. A. Cruz and B. J. Wiley, ACS Nano, 2019, 13, 6998-7009.

122 J. Zhao, Y. Lin, J. Wu, H. Y. Y. Nyein, M. Bariya, L. C. Tai, M. Chao, W. Ji, G. Zhang, Z. Fan and A. Javey, ACS Sens., 2019, 4, 1925-1933.

123 W. Liu, L. Yin, Q. Jin, Y. Zhu, J. Zhao, L. Zheng, Z. Zhou and B. Zhu, J. Electroanal. Chem., 2019, 832, 97-104.

124 Z. Liu, D. Ye, S. Wang, X. Zhu, R. Chen and Q. Liao, Ind. Eng. Chem. Res., 2020, 59, 15447-15453.

125 K. Saravanakumar and R. Rajeswari, Concurrency and Computation: Practice and Experience, 2019, 31, e5165.

126 Y. Chen, W. Ji, K. Yan, J. Gao and J. Zhang, Nano Energy, 2019, 61, 173-193.

127 S. Zhang, M. A. Zahed, M. Sharifuzzaman, S. Yoon, X. Hui, S. C. Barman, S. Sharma, H. S. Yoon, C. Park and J. Y. Park, Biosens. Bioelectron., 2021, 175, 112844.

128 S. Y. Oh, S. Y. Hong, Y. R. Jeong, J. Yun, H. Park, S. W. Jin, G. Lee, J. H. Oh, H. Lee, S. S. Lee and J. S. Ha, ACS Appl. Mater. Interfaces, 2018, 10, 13729-13740.

129 L. Manjakkal, W. Dang, N. Yogeswaran and R. Dahiya, Biosensors, 2019, 9, 14.

130 H. Im, H. Moon, J. Lee, I. Chung, T. Kang and Y. Kim, Nano Res., 2014, 7, 443.
131 M. Schönig and R. Schuster, Appl. Phys. Lett., 2020, 116, 091601.

132 A. Kundu and T. S. Fisher, Electrochim. Acta, 2018, 281, 357369.

133 H. Fathabadi, IEEE Trans. Veh. Technol., 2018, 67, 92419248.

134 I. S. McKay, L. Y. Kunz and A. Majumdar, Sci. Rep., 2019, 9, 1-8.

135 D. W. Gerlach and T. A. Newell, Int. J. Energy Res., 2007, 31, 439-454.

136 L. He, Q. Zhang, C. Gong, H. Liu, F. Hu, F. Zhong, G. Wang, H. Su, S. Wen, S. Xiang and B. Zhang, Sens. Actuators, B, 2020, 310, 127842.

137 H. Wang, Q. Han, X. Ren, H. Wang, X. Kuang, D. Wu and Q. Wei, J. Electroanal. Chem., 2020, 876, 114497.

138 J. Zhang, Y. Gao, P. Liu, J. Yan, X. Zhang, Y. Xing and W. Song, Electrochim. Acta, 2021, 365, 137392.

139 L. Tang, X. Ouyang, B. Peng, G. Zeng, Y. Zhu, J. Yu, C. Feng, S. Fang, X. Zhu and J. Tan, Nanoscale, 2019, 11, 1219812209.

140 J. Gao, Y. Chen, W. Ji, Z. Gao and J. Zhang, Analyst, 2019, 144, 6617-6624.

141 B. Peng, L. Tang, G. Zeng, S. Fang, X. Ouyang, B. Long, Y. Zhou, Y. Deng, Y. Liu and J. Wang, Biosens. Bioelectron., 2018, 121, 19-26.

142 B. Zhang, H. Wang, J. Xi, F. Zhao and B. Zeng, ACS Sens., 2020, 5, 2876-2884.

143 D. Y. Guo, K. Chen, S. L. Wang, F. M. Wu, A. P. Liu, C. R. Li, P. G. Li, C. K. Tan and W. H. Tang, Phys. Rev. Appl., 2020, 13, 024051.

144 G. Wang, J. Xu and H. Chen, Sci. China, Ser. B: Chem., 2009, 52, 1789.

145 L. Ge, H. Li and X. Du, Biosens. Bioelectron., 2018, 111, 131137.

146 C. B. Vining, Nat. Mater., 2009, 8, 83-85.

147 S. K. Chaudhuri and D. R. Lovley, Nat. Biotechnol., 2003, 21, 1229-1232.

148 J. H. Kim and T. J. Kang, ACS Appl. Mater. Interfaces, 2019, 11, 28894-28899.

149 J. N. Clifford, E. Martínez-Ferrero, A. Viterisi and E. Palomares, Chem. Soc. Rev., 2011, 40, 1635-1646.

150 K. Obata, L. Stegenburga, Y. Zhou and K. Takanabe, ACS Sustainable Chem. Eng., 2019, 7, 7241-7251.

151 A. J. Bandodkar, P. Gutruf, J. Choi, K. Lee, Y. Sekine, J. T. Reeder, W. J. Jeang, A. J. Aranyosi, S. P. Lee, J. B. Model, R. Ghaffari, C. J. Su, J. P. Leshock, T. Ray, A. Verrillo, K. Thomas, V. Krishnamurthi, S. Han, J. Kim, S. Krishnan, T. Hang and J. A. Rogers, Sci. Adv., 2019, 5, eaav3294.

152 G. Zhu, Z. H. Lin, Q. Jing, P. Bai, C. Pan, Y. Yang, Y. Zhou and Z. L. Wang, Nano Lett., 2013, 13, 847-853.

153 Y. Yang, Nanoenergy Adv., 2021, 1, 1-2. 